\title{
Ecology \& Its Applications in Local Architecture
}

\author{
Munaf Adnan Talib \\ Architectural Department, College of Engineering, University of Baghdad, Iraq \\ Munaf_dell@yahoo.com \\ Zaynab Radi Abaas \\ Architectural Department, College of Engineering, University of Baghdad, Iraq \\ Dr.zaynabr.a@coeng.uobaghdad.edu.iq
}

\begin{tabular}{|l|l|l|}
\hline Submission date:- 5/3/2019 & Acceptance date:- 28/3/2019 & Publication date:-5/5/2019
\end{tabular}

\begin{abstract}
The theories of interaction with the environment, considered as the most important and efficient theories currently in use, especially in the local urban environment, which has become far from the interaction with the environment. From here, we note that there is a lack of knowledge about the simulation of the performance of the interaction with the local environment through a computer model in order to achieve thermal comfort for users and rationalize the use of local environmental resources. Therefore, the research presents a theoretical framework for the definition of feasibility, its potential and its applications in an attempt to reduce the gap between technological development in the world, especially in the possibilities of simulating interaction with the environment, and the local reality. It also provides a practical framework through the application of computer simulations based on the analysis of a set of theories and to find the efficiency of its performance. This application is based on the creation of a virtual model of a multi-story building before and after the application of computer simulation and trying to achieve better thermal comfort values for the occupants of the building through the use of a certain programs, most notably (Rhino, Grasshopper, RayMan). The results showed the efficiency of using computer simulation programs to achieve better thermal value for the occupants. The research led to the development of a local multi-storey building that is climate efficient by following the design mechanisms derived from the climate of the region and thus achieving a climatic environment with optimal performance according to the comfort standards Thermal.
\end{abstract}

Key words: Ecology, Performance, Simulation, Modeling, Thermal comfort. 


\title{
التبيؤ وتطبيقاته في العمارة المحلية
}

\author{
مناف عدنان طالب \\ قسم هندسة العطارة، كلية العندسة، جامعة بغد/د، العراق \\ Munaf_dell@yahoo.com \\ زينب راضي عباس \\ قسم هندسة العمارة، كلية العندسة، جامعة بغد/د، العراق
}

Dr.zaynabr.a@coeng.uobaghdad.edu.iq

تعد نظريات التفاعل مع البيئة، من أهم و أكفأ النظريات المتداولة في الوقت الحالي، نظراً الى ما آلت اليه العمارة،

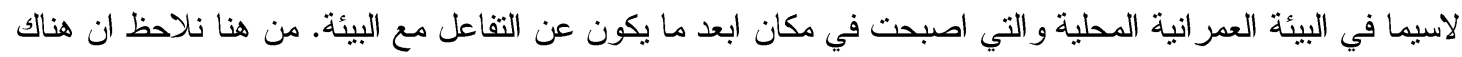

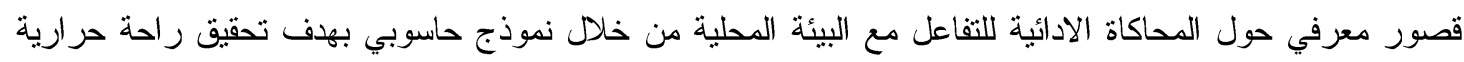
للمستخدمين وترشيد استخدام موارد البيئة المحلية. لذلك يقدم البحث اطار انظريا شموليا للتعريف بالتبيؤ وامكاناته وتطبيقاته، في محاولة لتقليل الفجوة بين التطور التكنولوجي عالميا -لاسيما في امكانات محاكاة التفاعل مع البيئة-وبين

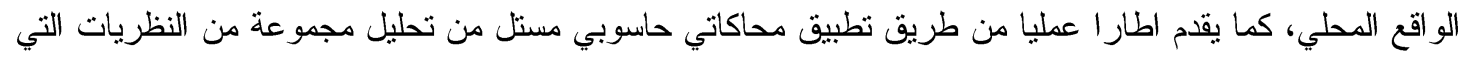

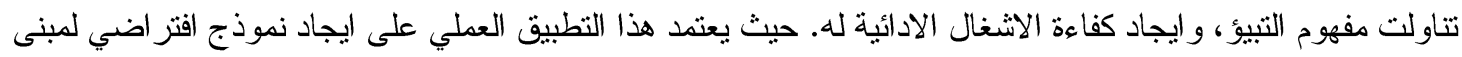

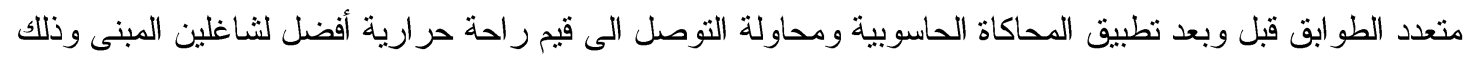
من طريق استعمال مجموعة من البر امج، اهمها (Rhino, Grasshopper, RayMan). وقد بينت النتائج كفاءة استخدام

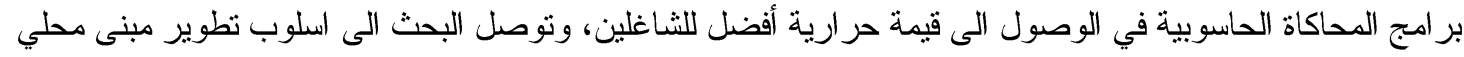

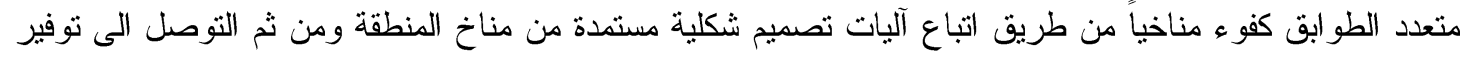

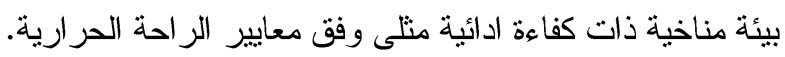
الكلمات الدالة: النبيؤ ، الادائية، المحاكاة، الندذجة، الر احة الحر ارية

1 المقدمة

اليوم وفي ظل التظور التكنولوجي المنسارع، لاسيما في مجال الحفاظ على البيئة و التفاعل معها، والذي يصب بطريقة او

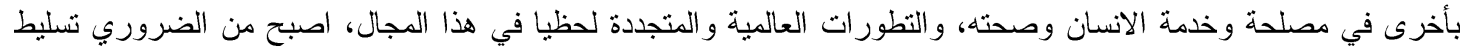
الضوء على سبل وتثانات و استر اتيجيات التفاعل مع البيئة و أهميتها ودور ها في تحقيق بيئة عمر انية نابعة من البيئة الطبيعية المحلية،

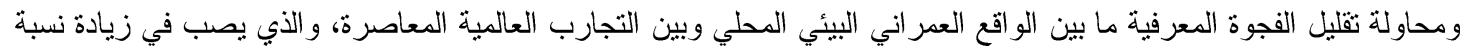

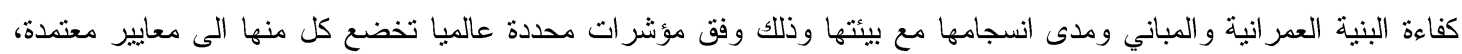

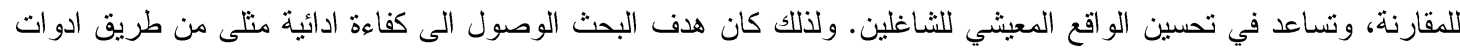

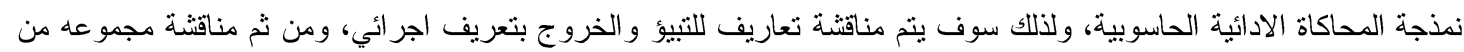
أحدث و اهم نظريات التييؤ لاستخر اج أهم العو امل المشتركة بينها، ولاستخر اج تعريف التييؤ في العمارة، ومن ثم محاولة استكثاف

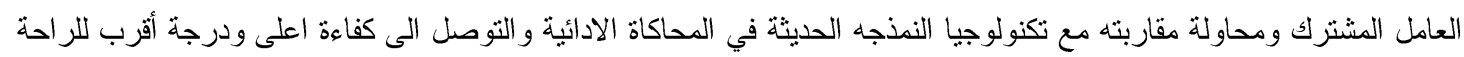

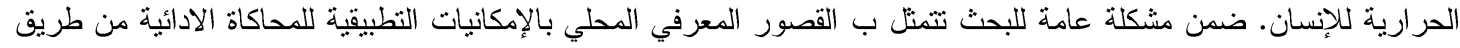

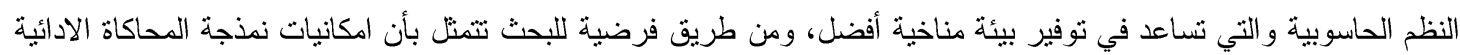
الحاسو يية نساعد في الوصول الى كفاءة ادائية منلى في عمارة الييئة المحلية. 


\section{r ـ المفاهيم العامة للتبيؤ}

ان مصطلح التبيؤ مفهوم شامل، بمدى واسع جدا يشتمل على العديد من التخصصات، ان مصطلح التبيؤ هو فعل مثتق بشكل اساسي من مفردة البيئة، وبذلك سيكون ارتباط المصطلح بشكل اساس بعلم البيئة، و علم البيئة أو علم التبيؤ Ecology: هو العلم

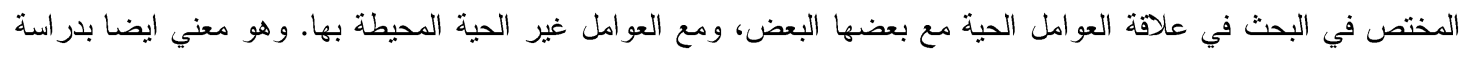

وضع الكائن الحي في موقعه، اضافة الى محيطه الفضائي. [1].

r 1 (التعاريف العامة

يمثل علم التييؤ Ecology :علم العلاقات بين الكائنات الحية وبيئاتها وتسمى أيضا الإيكولوجيا، كذلك عرف بانه فرع من

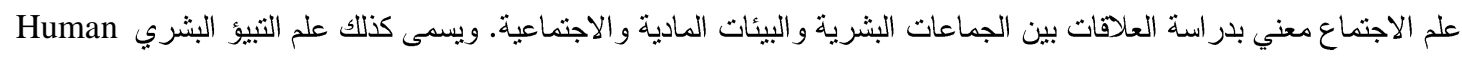

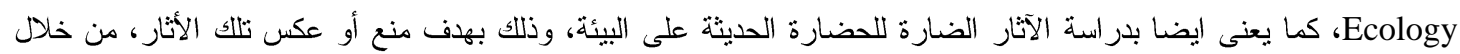

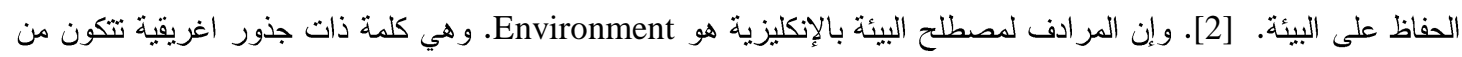

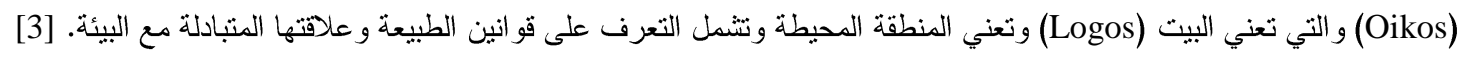

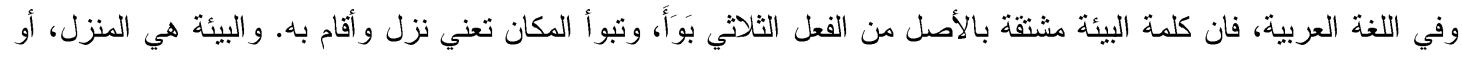

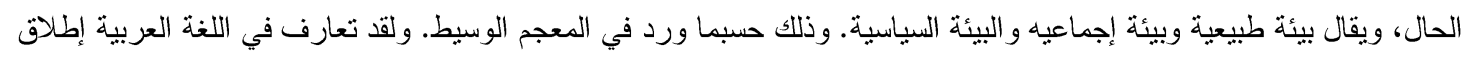

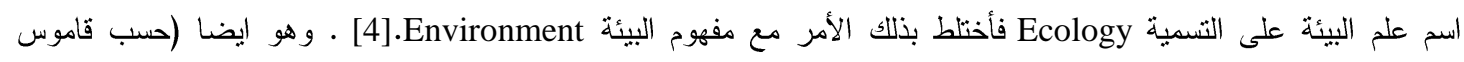

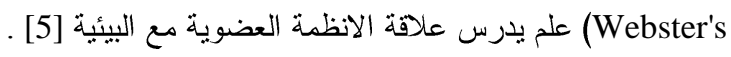

r r r ارتباطات مفاهيم التبيؤ

أ- التصميم الايكولوجي Eco Design: هو نهج لتصميم المنتجات مع إيلاء اعتبار خاص للآثار الييئية للمنتج خلال دورة حياتها بأكملها. في تقييم دورة الحياة، عادة ما تتقسم دورة حياة المنتج إلى عمليات الثراء و التصنيع والاستخدام و التخلص منها اخيرا.

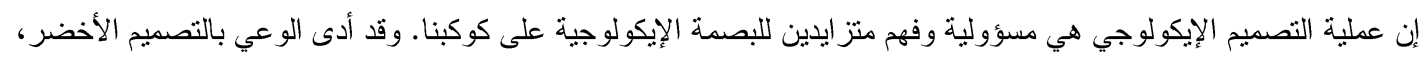

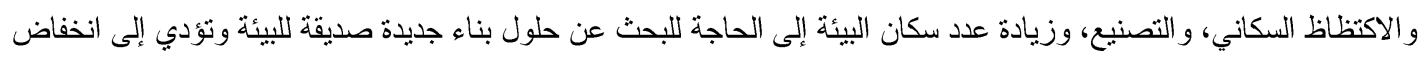

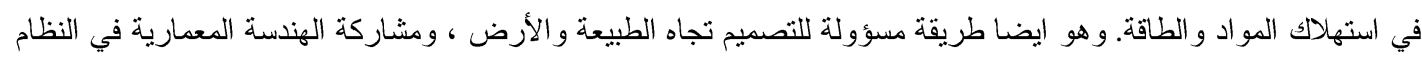
الحي من خلال فهمه وإدماجه في البنية غير الحية كمباني في النظام الحي؛ إنه نظام إيكولوجي صناعي من خلال الهياكل و المباني

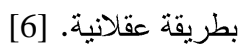

ب- الايكولوجيا التكنولوجية:Eco Technology هو العلم التطبيقي الذي يسعى إلى تلبية الاحتياجات البشرية هع التسبب في الحد

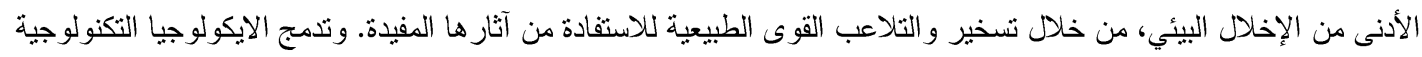
مجالين من مجالات الدر اسة: "بيئة التقنيات" و "تقنيات الإيكولوجيا"، مما يتطلب فهم هياكل و عمليات النظم الإيكولوجية و المجتمعات.

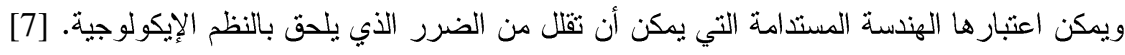

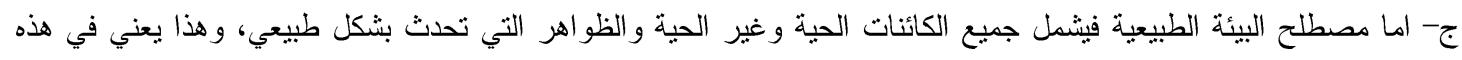
الحالة انها ليست مصطنعة. وكثير ا ما ينطبق هذا المصطلح على الأرض أو على بعض أجز اء الأرض. وتتشل هذه البيئة تفاعل

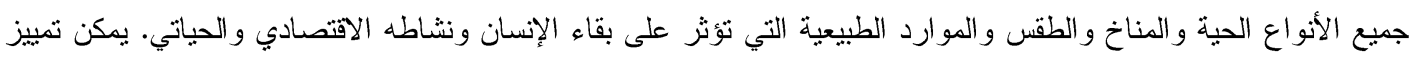

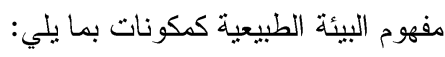
1- الكائنات البيئية القائمة بحد ذاتها و التي تعمل كنظم طبيعية دون تدخل إنساني متحضر ضخم، بما في ذلك جميع النباتات و الكائنات الحية الدقيقة والتزبة و الصخور و الغلاف الجوي و الظواهر الطبيعية التي تحدث داخل حدودها وطييعتها. [8]. r- المو ارد الطبيعية العالمية و الظو اهر الفيزيائية التي تفتقر إلى حدود و اضحة مثل الهو اءو والماء و المناخ، فضلا عن الطاقة و الإثعاع و الثحنة الكهربائية و المغناطيسية، التي لا تتبع من النشاط البشري المتحضر . 
و على النقيض من الييئة الطيبعية هي البيئة المبنية. وفي المناطق التي قام فيها الإنسان بتحويل جذري للمناظر الطبيعية مثل

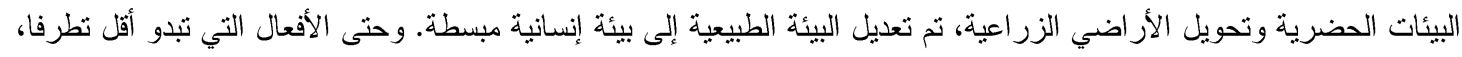

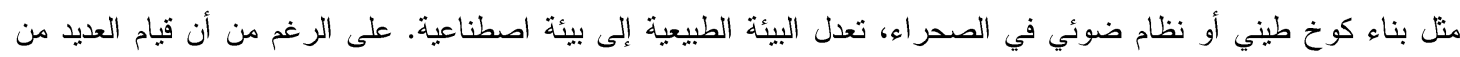

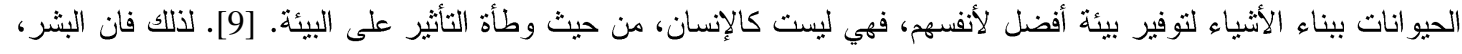

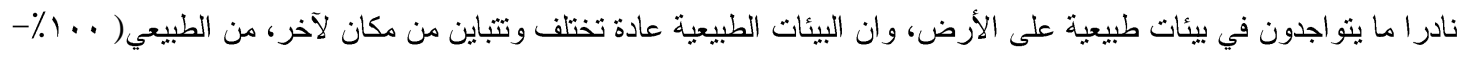

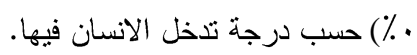

لذلك ومما تقام يتم تعريف التبيؤ بوصفه: مفهوم شامل يؤشر تفاعل النتاج مع بيئته الثي ينبع منها من حيث الاستجابة

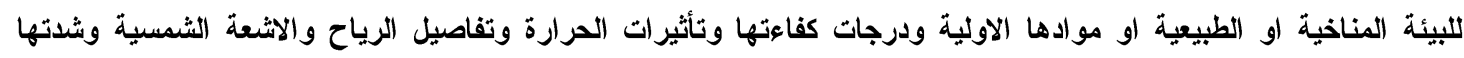

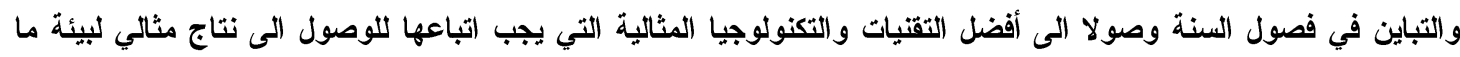
و الأي يعد الآسان هو الحكم الاساس في تأثنبر نجاحه.

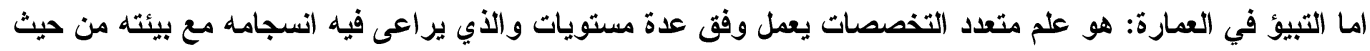

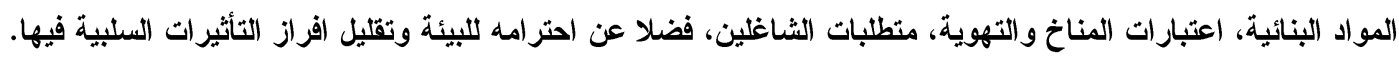

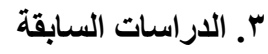
حيث ستتاول هذه الفقرة اهم الهفاهيم التي جاءت بها مجمو عة من اهم الدراسات الني تتاولت موضو عات التيبؤ، و تثقديم تحليل لجو انب لكل دراسة، وتعريف تخصصاتها الدقيقة وذلك للقيام باستحصال اهم المفاهيم و المبادئ المشتركة التي تناولها مفهوم التنييؤ

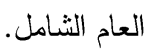

The Ecology of Building Material, Bjørn Berge, 20091.3

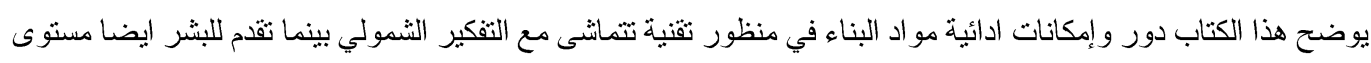

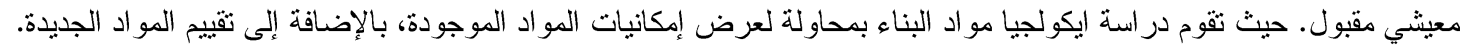

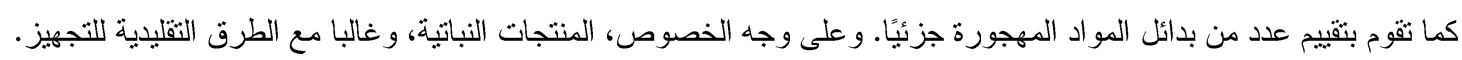

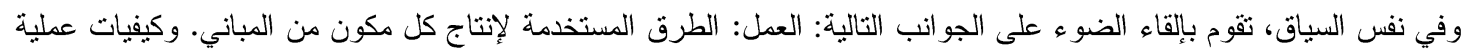

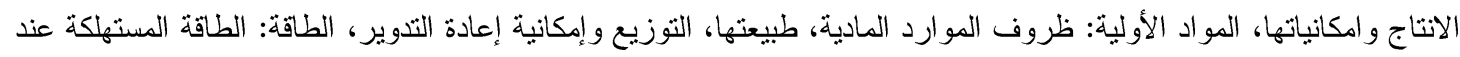

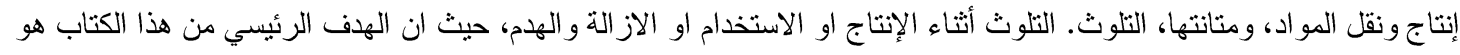

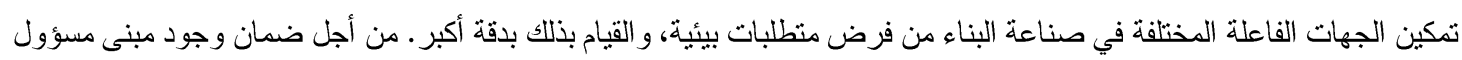

بيئيًا [10]

\section{Versatility and Vicissitude (Performance in Morpho-Ecological Design) 2.3}

\section{Michael Hensel and Achim Menges, 2008}

يعيد هذا العدد من المجلة نعريف مفهوم الادائية و الذي يهذف الى تحريك النقاش كليا حول هذا الموضوع، ويشرح ناثير

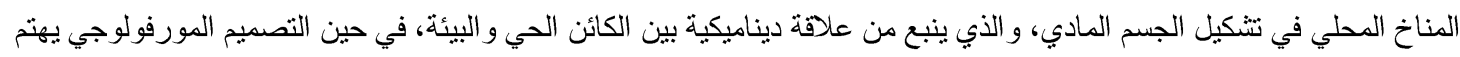

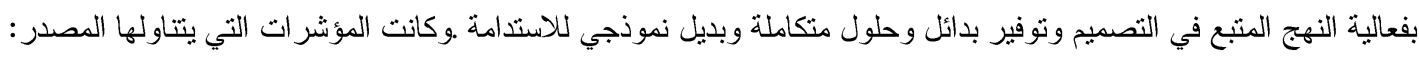
أ -تناول المصدر المصطلحات التالية: الثنكل، القوة، الأداء، متعدد الهيكلية، التصميم، الأيض والمورفولوجيا، التهية، أداء المواد، أداء

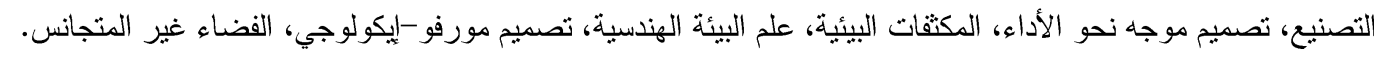
ب -صفة التتوع قادرة على تكييفها للعديد من الاستخدامات و المهارات الدختلفة، مثل الاختلاف أو التباين في الطبيعة. ج-أنو اع الهناخ واستجابة البناء لها او ما يسمى بالتقنيات الخضر اء، حيث ان الأداء يحدد من خلال التكامل مع المقياس المستدام للإِكان كتصميم بيو مناخي كوسيلة للحد من البصمة البيئية. 
د-مكونات التصميم البيولوجي الحيوي: أنواع المناخ ومنطلباته؛ الر احة الحر ارية التكيفية أدو ات و أساليب التقييم المناخ: مسار الثمس و الرياح و المطر العمل مع العناصر ، منل النظم السلبية و النشطة.

ه -تطوير استمارة استجابة للمساكن المناخية البيولوجية كطريق نحو الاستيطان الحضري المستدام وتقديم استر اتيجيات متقدمة للنظم السليية و النشطة للتحسين المناخي و البيئي ولتخطيط الموقع وربط تخطيط المباني وتصميم الاحاطات المادية التي من شانها تحسين المناخ واختيار الأنظمة الميكانيكية التي تعمل مع تخطيط المباني واحاطة المبنى من طريق الهندسة المعمارية البيولوجية الحيوية.

\section{3 دور مناهج محاكاة الطبيعة في استر اتيجيات البناء الشكلي المستدام، اكرم العكام و سامال بابان، ^ . . ب}

يهدف البحث الى الكثف عن تأثثر مناهج محاكاة الطبيعة على استر اتيجيات البناء لثكلي المستدام، مفترضا تأثر استر اتيجيات البناء الثنكلي المستدام بمناهج محاكاة الطبيعة. أعتمد البحث المنهج الوصفي التحليلي، و استمارة الملاحظة المصممة من قبل الباحث،

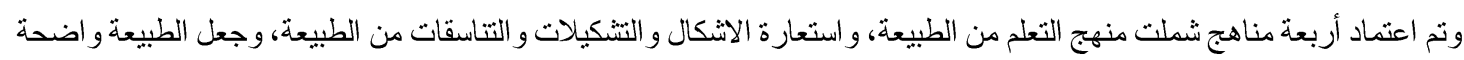

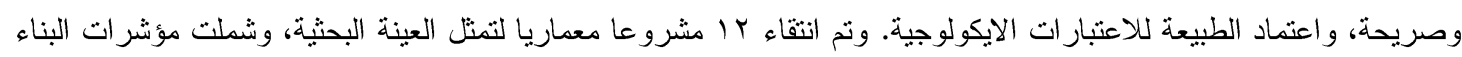

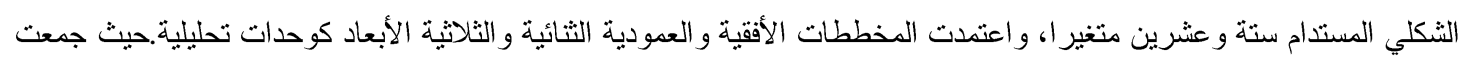
البيانات خلال ثلاثة أوجه مسحية استغرقت لمعاملة البيانات ومن خلال الحقيبة الاحصائية قرابة ستة اثهر ومن خلال استخدام

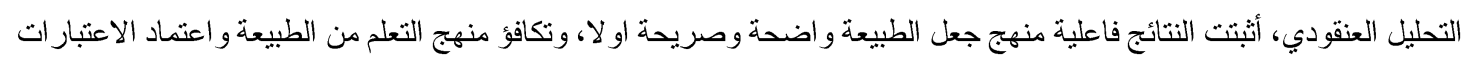
الأيكولوجية كأساس للتشكيل ثانيا، وضعف فاعلية منهج استعارة الاشكال والتشكيلات من الطبيعة مع استر اتيجيات البناء الثنكلي

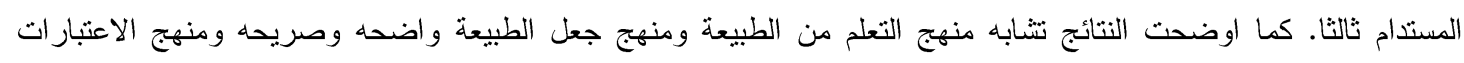
الأيكولوجية كأساس للتشكيل في الاعتماد على انسجام الثكل و التحامه مع السياق الخارجي وتكامله معه من خلال شفافية بعض وضل

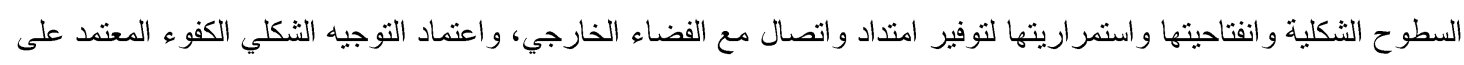

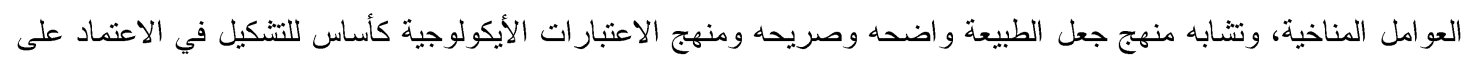

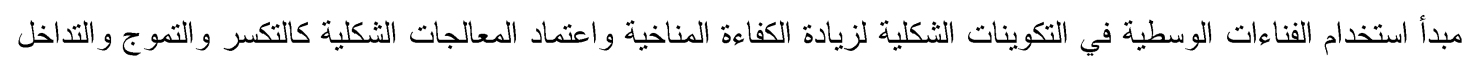
و التدرج للتقليل من الكسب و الفقدان الحر اري، وجعل الطبيعة واضحه وصريحه في استخدام الألوان الموسمية والمو اد العاكسة للتقليل

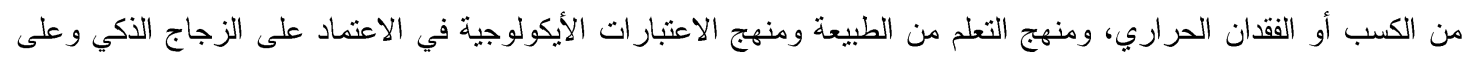

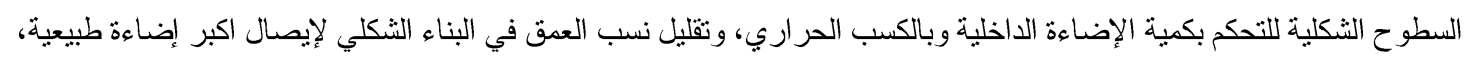

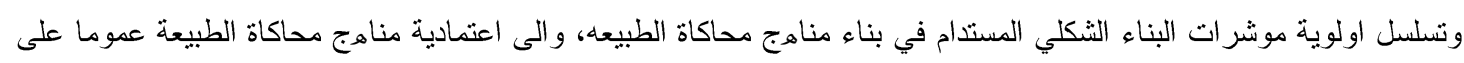

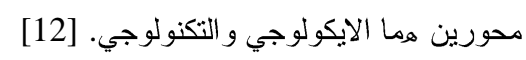

\subsection{Adaptive[Skins]: Responsive Building Skin Systems Based On Tensegrity Principles}

\section{Sushant Verma, Pradeep Devadass, 2013}

يبحث المصدر في أنظمة القترة المبنية على الاستجابة البيئية والتي تتكيف مع الظروف البيئية الديناميكية لتنظيم الظروف

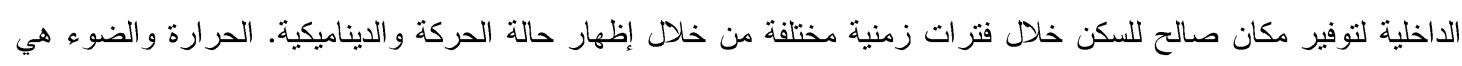
المؤشر ات الأساسية للتظيم، مما يؤدي إلى كفاءة الطاقة و التأثثر ات المكانية الديناميكية. يتم تطوير التصاميم القترية النشطة و الجاهزة التي تستخدم شر ائح ذاكرة ومشغلات تعمل بالهو اه المضغوط من خلال تقارير في الأنظمة الذكية التي تقوم بدمج المواد الذكية

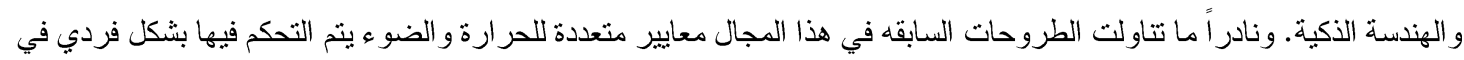
نظام و احد، و الذي تمت محاولة تفعيله في تطبيقات هذا المصدر • بسبب تعقبد النظام متعدد المعايير، يتم تطوير الخوارزميات الجينية لتحسين النظام ومعايرتها بنماذج مادية على مستويات مختلفة. يتم اختبار الأنظمة المطورة مقابل اثثين من النماذج المناخية المتميزة - نيودلهي وبرشلونة، وتقييمها للأداه، على أساس الحرارة و الضوء، والتي يتم قياسها كمكسب للطاقة الثمسية وإضاءة كمبادئ،

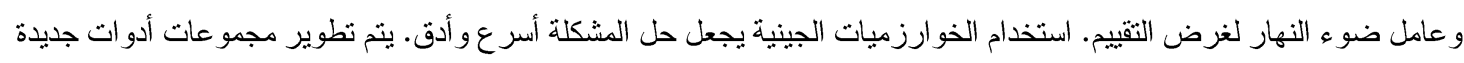
في العملية من خلال الجمع بين الأدوات الرقمية المختلفة، لإنشاء نظام ردود الفعل في الوقت الحقيقي ونظام للذاكرة التجميعية

التز اكمية. [13] 


\subsection{Principles and practice of ecological design Fan Shu-Yang,Bill Freedman, Raymond Cote, 2004}

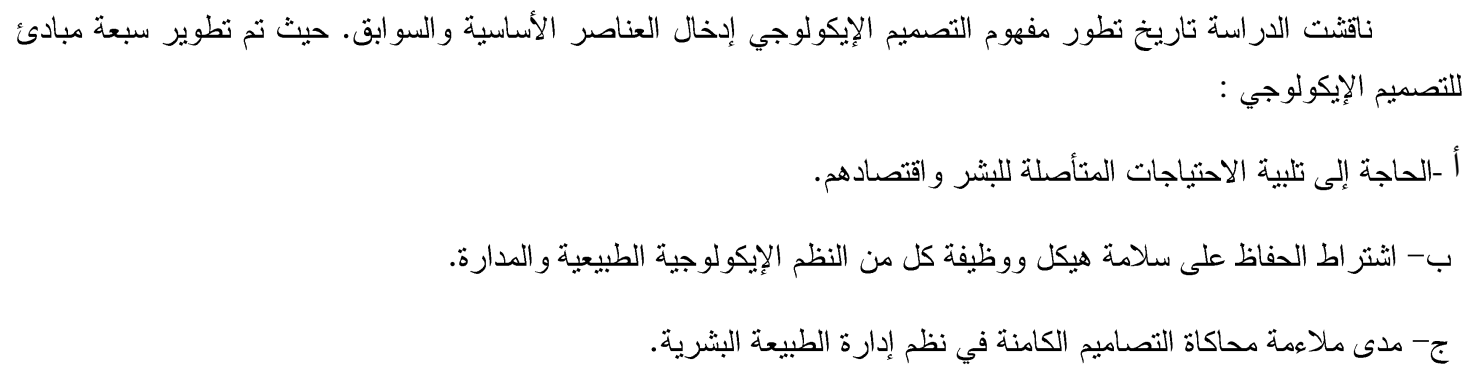

بعد الاطلاع على مجموعة من الار اسات الحديثة التي تناولت موضوع التبيؤ، سوف يتم تفصيل التخصصات ونوع التصميم وتصنيفها من طريق جدول (1)، الذي سبتناول ه دراسات مختلفة تم الاطلاع على اهم اهدافها لغرض تصنيف الهم تخصصات التبيؤ الفرعية وكما يالي:

\begin{tabular}{|c|c|c|c|}
\hline \multicolumn{4}{|c|}{ ع (التصميم للار اسات التي تناولت مواضيع التبيؤ في التصميم المعماري } \\
\hline المفردة الاسساسية & التخصص & الأدر اسة & $ث$ \\
\hline كفاءة مو اد البناء & العمارة الصديقة للبيئة & التييؤ في مو اد البناء & 1 \\
\hline Building material efficiency & Environmental friendly & The Ecology Of Building Materials & \\
\hline التصميم الموجه نحو الأداء & التصميم المورفولوجي & الادائية في التصميم الموروفلوجي & r \\
\hline $\begin{array}{l}\text { Performance-Oriented Design } \\
\text { Environmental Intensifiers } \\
\text { Engineering Ecologies } \\
\end{array}$ & $\begin{array}{l}\text { Morpho-ecological } \\
\text { design }\end{array}$ & Versatility and Vicissitude & \\
\hline العمارة المحلية & تقليد الطبيعة & دور مناهج محاكاة الطبيعة على استر اتيجيات & r \\
\hline Vernacular architecture & Biomimicry & 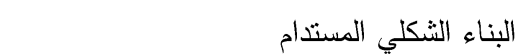 & \\
\hline العمارة المستجيبة للبيئة & العمارة الذكية & القشرة المتكيفة في المباني المستجيبة & $\varepsilon$ \\
\hline $\begin{array}{l}\text { Building response to the } \\
\text { environment }\end{array}$ & Intelligent Design & $\begin{array}{ll}\text { Adaptive[Skins]: } & \text { Responsive } \\
\text { Building Skin Systems } & \\
\end{array}$ & \\
\hline 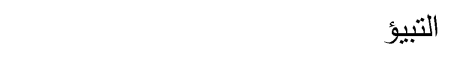 & التصميم الايكولوجي & المبادئ الاساسية للتصميم الايكولوجي & 0 \\
\hline Ecology & Ecological Design & $\begin{array}{l}\text { Principles and practice of ecological } \\
\text { design }\end{array}$ & \\
\hline
\end{tabular}


مما تقام في الجدول (1) ومن طريق الدراسات والبحوث و الكتب التي تناولت مفهوم التبيؤ في البيئة العمرانية، نجد ان

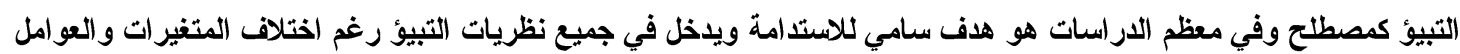

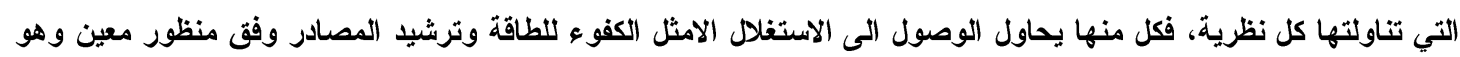

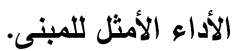

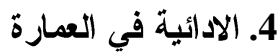

ان التطور الحاصل في الآونة الاخيرة لاسيما في مجالات التصميم بمكن ان تحقق من خلال جملة من الافكار الرئيسية

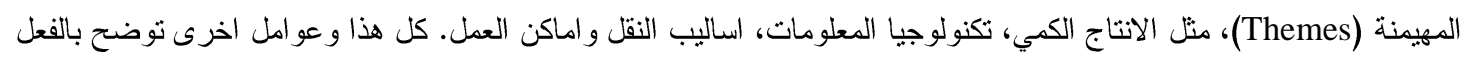

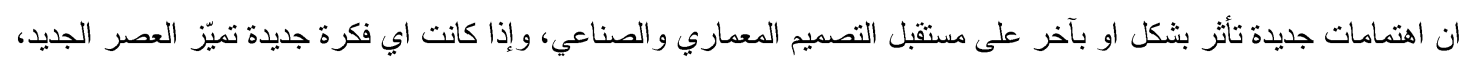

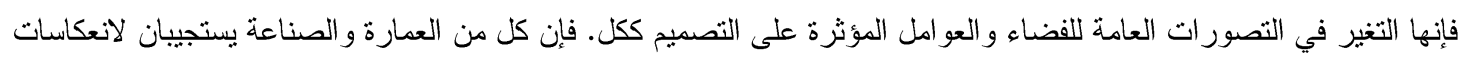

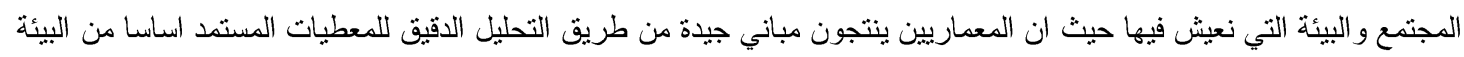

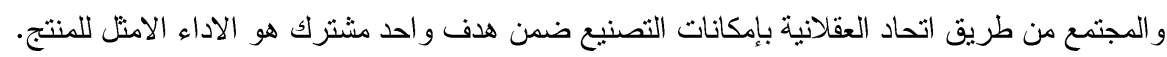

ع , التعاريف العامة

هنالك مجموعة من المصادر والمنظرين الذين قامو ا بتفسير مفهوم الادائية من خلال جملة من التعاريف التي تسلط الضوء

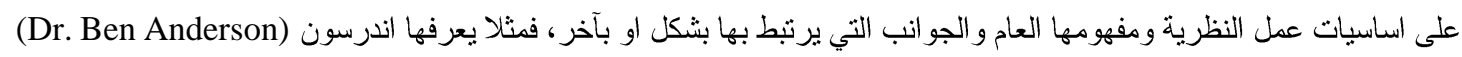

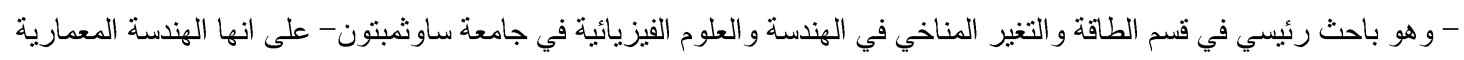

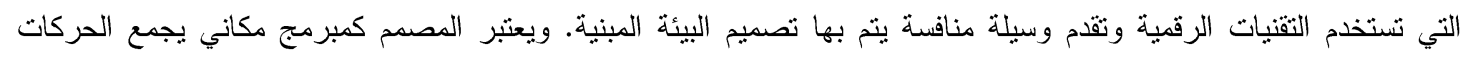

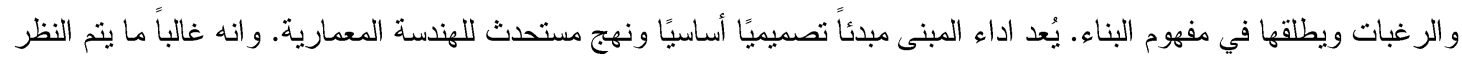

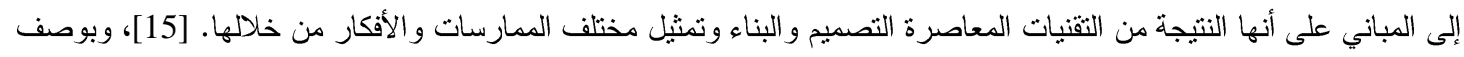

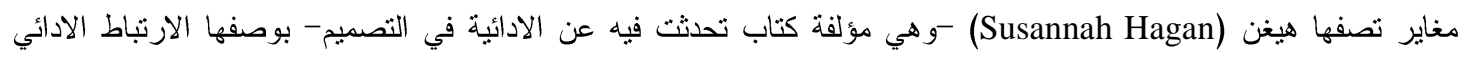

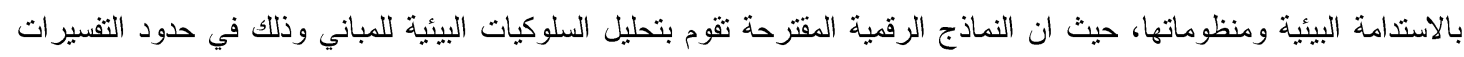

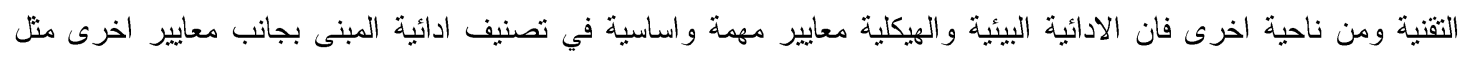

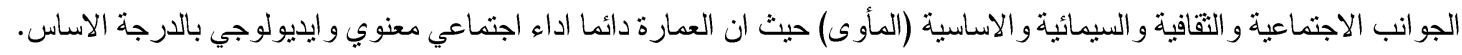

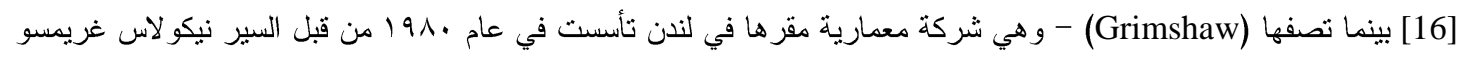

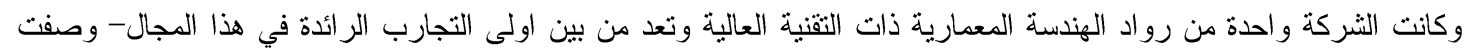

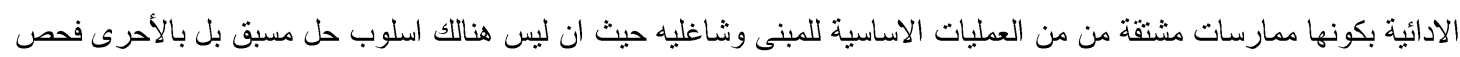

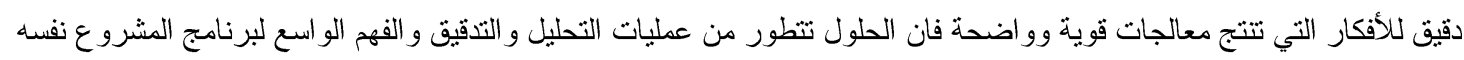

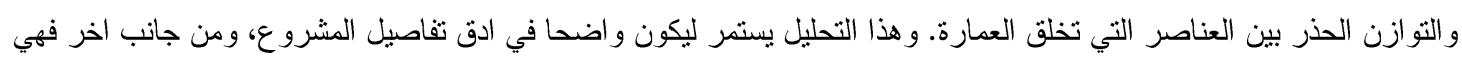

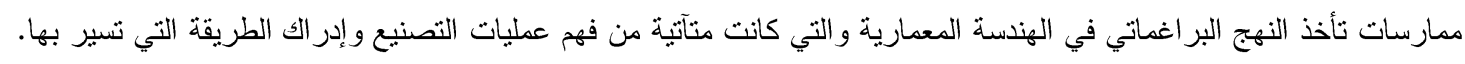

\section{؟ ؟ ب المحاكاة الادائية}

المحاكاة بثكل عام كتعريف للمصطلح هي عملية تقليد يعتمد على النقارب بين نموذج جديد ونموذج محاكى لتسبير العملية

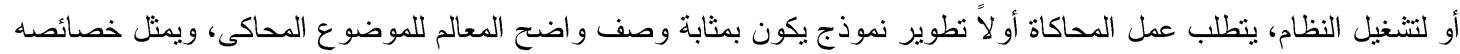

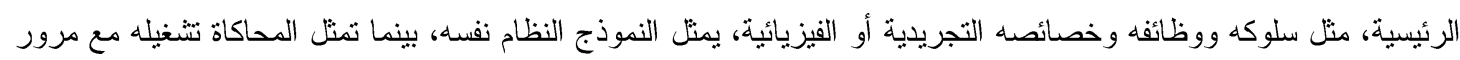

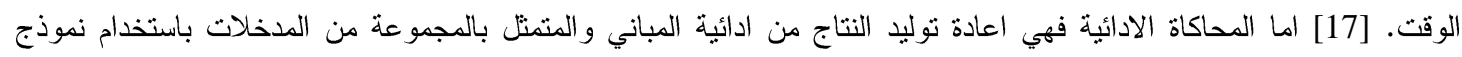

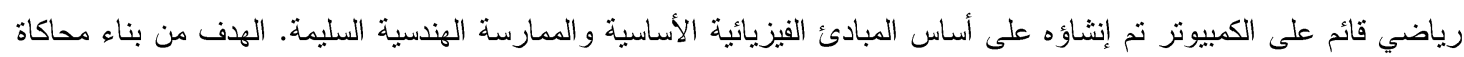

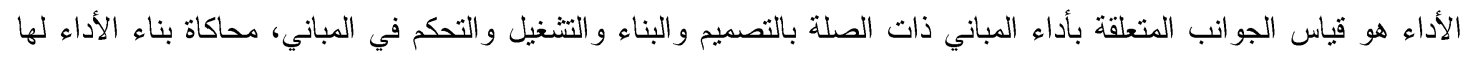

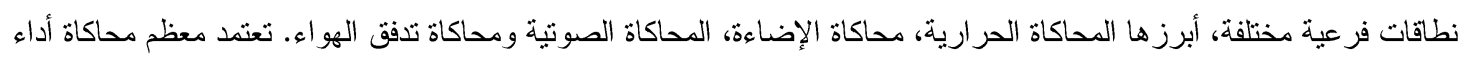


المباني على استخدام برامج المحاكاة المصمة حسب الطلب، محاكاة بناء الأداء في حد ذاتها هي حقل داخل المجال الأوسع للحوسبة

العلمية ويخضع لنفس قو انينها في التعامل. [18]

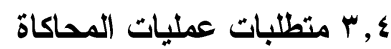

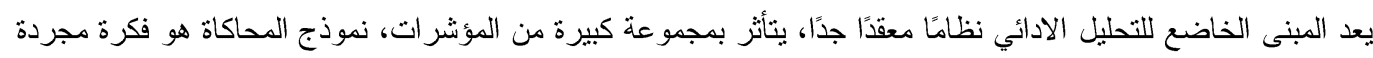
اللمبنى الحقيقي الذي بسمح بالنظر في النأثيرات على مستوى عال من التفصيل وتحليل مؤشرات الأداء الرئيسية دونما الحاجات

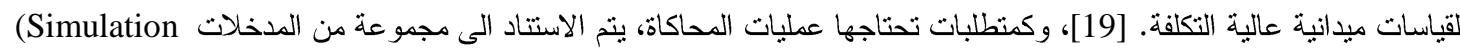
(inputs)

المناخ، الموقع، الثكل و النواحي الهندسية، الاحاطة المادية، مصادر الحر ارة الداخلية، نظام التهوية، الخو اص البشرية اضافة

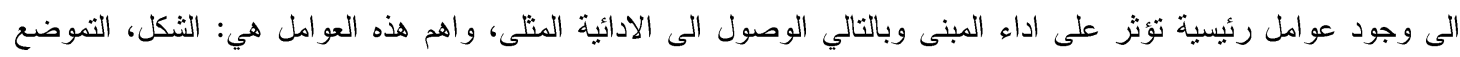
و التصميم الثنمسي، و الاعتبار ات الحضرية.

צ , ؛ مؤشر ات الادائية (Performance Indicators)

يؤدي الاداء دور اساسي في التوقعات التي عبر عنها اصحاب المباني او شاغليها، لاسيما في تطوير وصيانة هذه المباني

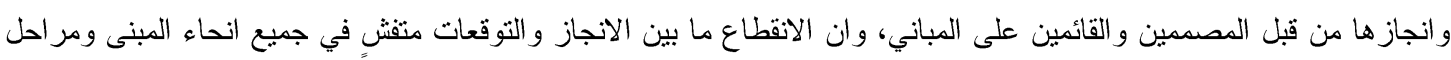

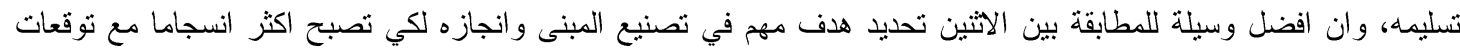

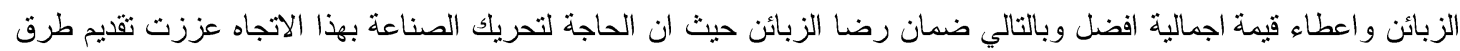
لإنشاء مبان معتمده على الاداء، وان هذه الطرق او الاساليب تركز على اتاحة متطلبات المبان المعتمدة على الاداء و على ادارة عملية شفافة تضمن لهم التوصل لهذه المنطلبات. و هذا يتطلب بشكل اساسي اساليب أفضل و ادوات منطورة لدعم التو اصل بين المصممين المعماريين، المهندين ومديري عمليات البناء. وهذا سوف يحتاج بطبيعة الحال الى معايير موضوعية يتم عن طريقها تقيبم هذا الاداء الخاص بالمباني وذلك للتوصل الى الحد الاعلى من توقعات شاغليها وتجنب الخسائر في الطاقة وتثفاعل بشكل أفضل مع البيئة

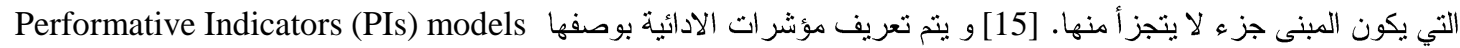
وهي معايير متفق عليها تعد وسيلة معتمدة في مجالات القياسات الادائية، والتي تعمل على تقييم نجاح اي منظمة او نشاط او تصميم (مثل المشاريع، البرامج، المنتجات والاعمال الاخرى) [20]،هناك العديد من انواع المؤشرات الادائية (مثل الراحة الحرارية) ويتم

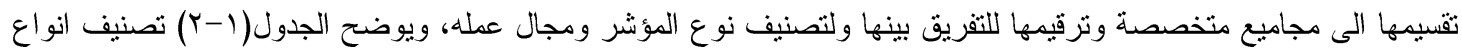
المؤشر ات:

\begin{tabular}{|c|c|c|c|}
\hline \multicolumn{4}{|l|}{ الادئية (PIs) وتقبيمها حسب المجال والوظيفة وترقيم المؤشر ات لكل وظيفة } \\
\hline 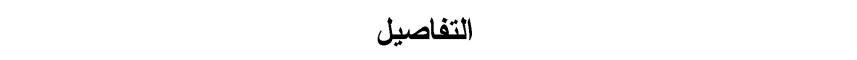 & (PI) & الوظيفة & 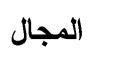 \\
\hline التبريد، التدفئة، الترطيب، الانارة، المضخات، المراوح، كمية الطاقة & PI 1-7 & الطاقة & الطاقة \\
\hline استهلاك طاقة الإضاءة الكهربائية خلال مستوى الإضاءة المطلوب للوحدة: & PI 1 & \multirow{3}{*}{ كفاءة الطاقة } & \multirow{6}{*}{ 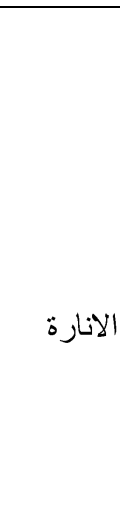 } \\
\hline فعالية الاستتارة من تز اكيب الاضاءة :(لومين / و اط) & PI 2 & & \\
\hline النسبة المئوية للساعات التي لا تتطلب إضاءة اصطناعية & PI 3 & & \\
\hline نسبة عمل الاضاءة المركبة والاضاءة المطلوبة & PI 4 & الر احة البصرية & \\
\hline أرؤية الخارجية : النسبة المئوية للمستخدمين الذين يمكنهم رؤية الخارج من & PI 5 & \multirow[b]{2}{*}{ الر احة البصرية - الة } & \\
\hline تجنب وهج النهار : النسبة المئوية لساعات العمل في نطاق غير مريح (مؤشر & PI 6 & & \\
\hline
\end{tabular}




\begin{tabular}{|c|c|c|c|}
\hline اجهزة التظليل لتفادي الوهج (تحت التطوير) & PI 7 & & \\
\hline النتسبة المئوية للمستخدمين في الراحة حسب مؤشر (ADPI) (مؤشر ادائية & PI 1 & انتشار الهو اء & \\
\hline 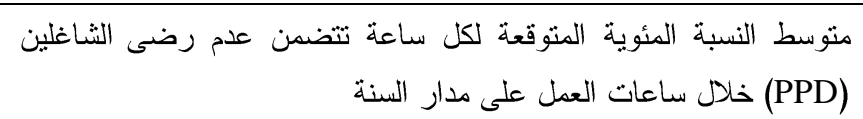 & PI 2 & المتباين & 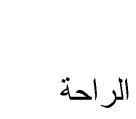 \\
\hline النسبة المئوية للساعات التي يكون فيها (PPD) في نطاق الراحة (• . ٪) & PI 3 & 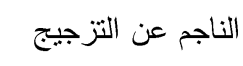 & 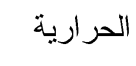 \\
\hline متوسط (PPD) حيثما تكون (PPD) لبست في نطاق الراحة & PI 4 & & \\
\hline متوسط (PPD) لكل ساعة خلال ساعات العمل مدار عام & PI 5 & 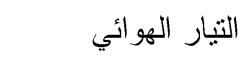 & \\
\hline النسبة المئوية للساعات التي يكون فيها (PPD) في نطاق الراحة (· ( ٪) & PI 6 & الناجم عن التزجيج & \\
\hline متوسط (PPD) حيثما تكون (PPD) ليست في نطاق الر احة & PI 7 & & \\
\hline متوسط (PPD) للعاملين في مختلف الأنشطة و مستويات الملابس & PI 8 & 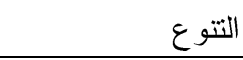 & \\
\hline التتوع في تدفق هو اء التدفئة في غرف مختلفة في نطاق الراحة الحرارية & PI 9 & ت تصيص المكاني & \\
\hline التتوع في تدفق هو اء التبريد في غرف مختلفة في نطاق الراحة الحرارية & PI 10 & & \\
\hline الذواني المطلوبة لزيادة درجة حرارة المنطقة ب ا درجة مئوية في وقت & PI 11 & قاسرة النظام وسر عة & \\
\hline
\end{tabular}

حيث يبين الجدول اعلاه اهم المجالات التي يعبر عنها بواسطة المؤشرات الادائية وتفصيلها حسب الوظيفة ومن ثم تفاصيل كل نوع من هذه المؤشرات، نلاحظ ان المصطلح الاهم المعتمد هو الراحة للساكنين والذي يعتبر المقياس الاهم في تقييمات الادائية

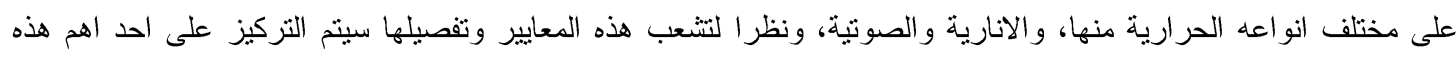
المجالات وهي الراحة الحر ارية، و التي ستحتاج بالتالي الى معايير معتمدة ومتبعه لقياس هذه المؤشرات بشكل دقيق في عمليات التحليل الادائي و التصميم و غير ها تسمى بمعايير الر احة الحر ارية للساكنين.

ع ,ه معاييز الراحة الحرارية

الر احة الحر ارية: إن الحالة الذهنية التي تعبر عن الرضا عن البيئة الحرارية وهي جانب مهم من عملية تصميم المبنى كون الانسان اليوم يقضي معظم يومه في البيئة الداخلية. [22]، و هناك عو امل اساسية تؤثر في الوصول للر احة الحر ارية، تقسم في فئتين هما: العو امل الثخصية: والتي تخص شاغلين المبنى، مثل: معدل الأيض ومستوى الملابس، و العو امل البيئية: هي ظروف البئية البيئة

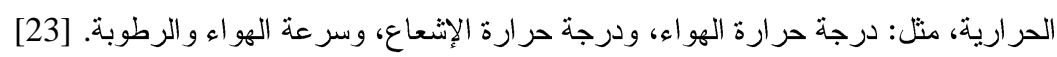

؟ , צ المعايير القياسية (Standard model)

و هي المعايير المتفق عليها والتي يتث عن طريقها قياس المؤشرات لاختبار الراحة الحر ارية في البيئات المختلفة، وهناك انو اع

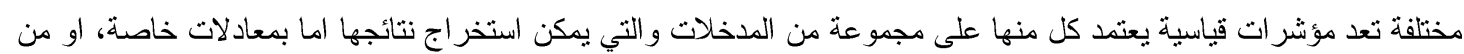
طريق بر امج حاسوبية خاصة تعتمد خو ارزميات خاصة لاستتناج تلك الارقام التي يتم مقارنتها مع تلك المعايير ، وسوف يتم في هذه الفقرة استعر اض اهم تلك المعايير:

أ- معيار (PMV): Predicted Mean Vote متوسط التصويت المتوقع: وتكون عبارة عن استطلاعات للر احة الحر ارية القياسية تسال المستخدمين عن مو اضيع حول إحساسهم الحراري على مقياس من سبع نقاط من البرد (-r) إلى الحار (+r). تم تطوير نموذج P.O. Fanger بو باستخدام معادلات ميز ان الحرارة و الدر اسات التجريبية حول درجة حر ارة الجلد لتحديد الر احة الحر ارية. تستخدم معادلات Fanger لحساب متوسط الأصوات المنوقعة (PMV) لمجمو عة كبيرة من التخصصات

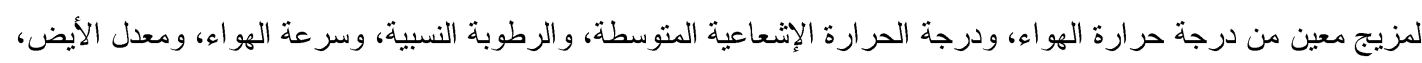

$$
\text { وعزل الملابس. [24] }
$$

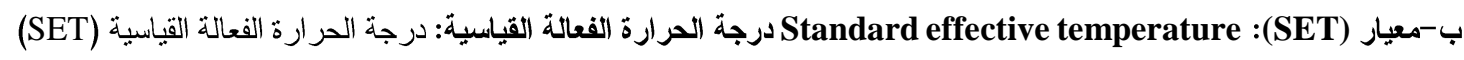
هي نموذج استجابة الإنسان للييئة الحرارية. تم تطويره بواسطة A.P. Gagge وقبله ASHRAE في عام 919 ا ـ ويشبه في 
حساباته حسابات معيار (PMV) لأنه مؤشر شامل للراحة بعتمد على معادلات توازن الحرارة التي تتضمن العوامل الثخصبة

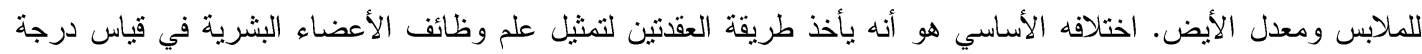

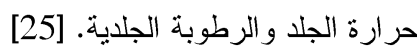

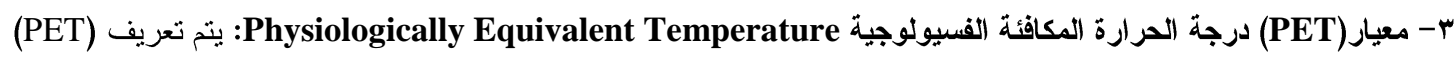

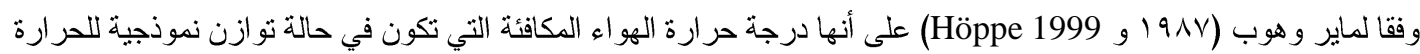

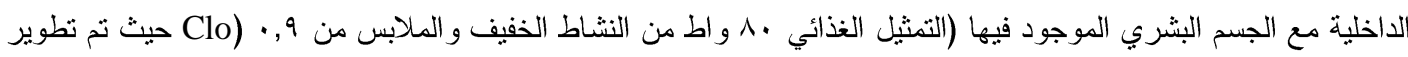

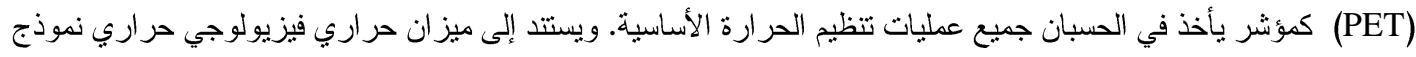

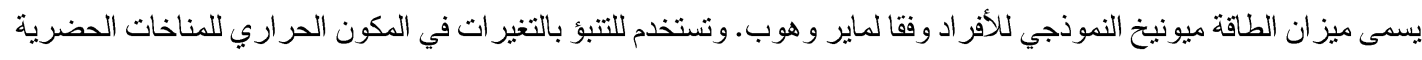

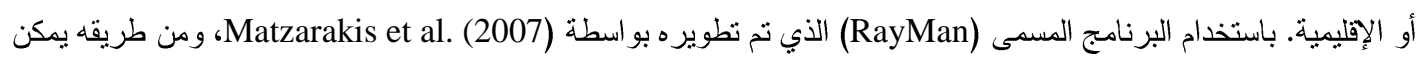

حساب (PET) (26) بسهولة. (26)

بعد شرح المعايير الثلاثة المنتخبة لقياس الراحة الحرارية وتعريف مؤثر اتها وعواملها التي تؤثر في صياغة قيمها، سوف

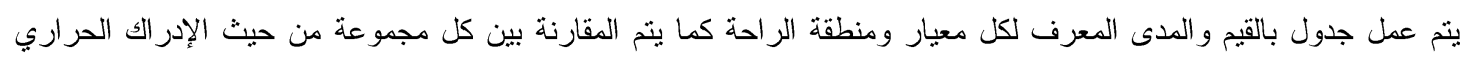

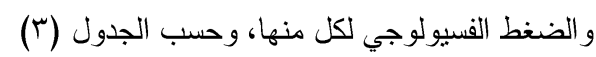

\begin{tabular}{|c|c|c|c|c|}
\hline \multicolumn{5}{|c|}{ 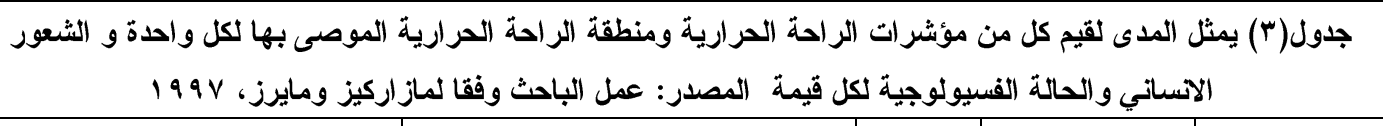 } \\
\hline الحالة القسيولوجية & الاحساس & \begin{tabular}{l|l|} 
PET \\
\end{tabular} & SET & PMV \\
\hline الفشل في نظام التبخر & حار جدا، غير مريح مطلقا & $\varepsilon$ & $>37.5$ & $>3.5$ \\
\hline تعرق غزير & حار، غير مقبول جدا & ro & $r \leqslant, 0-r v, 0$ & +2 to +3 \\
\hline ت تعرق & دافئ،غير مريح، غيرمقبول & rq & $r \cdot-r \leqslant, 0$ & +1 to +2 \\
\hline تعرق بسيط، توسع الاو عية & دافئ قليلا، غبرمقبول قليلا & rr & $r 0, T-r$. & +0.5 to +1 \\
\hline استثر ار فسيولوجي & مريح كمقبول & 11 & YY,Y-YO, T & $-0.5,+0.5$ \\
\hline ضيق الاوعية الاولي & بارد قليلا، غبر مقبول قليلا & 14 & $I V, O-Y Y, Y$ & -1 to -0.5 \\
\hline تبريد بطيء للجسم & بارد، غير مقبول & $\wedge$ & $1 \leqslant, 0-1 V, 0$ & -2 to -1 \\
\hline بداية الارتعاش & بارد جدا، غير مقبول مطلقا & $\varepsilon$ & $1 \cdot-1 \leqslant, 0$ & -3 to -2 \\
\hline
\end{tabular}




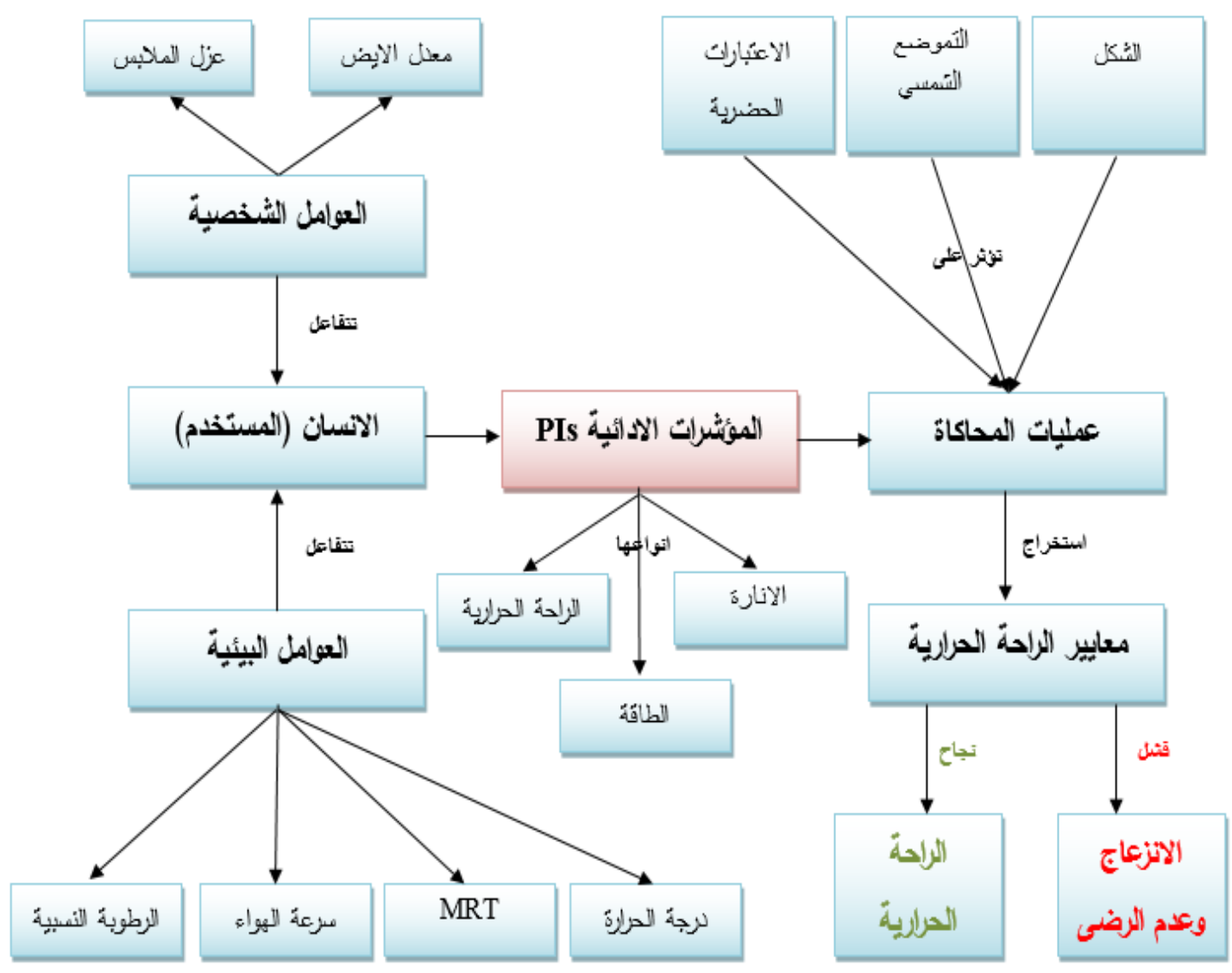

\section{شكل ( ) يوضح ارتباطات المؤشرات الادائية و العو امل المؤثرة فيها وامكانيات نتائجها وعلاقتها بالر احة الحرارية}

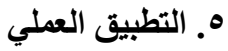

وفقا لما تم ذكره آنفا، توضح ان هناك مجمو عة من مؤشر ات لقياس الادائية في المباني (PIs models) او Performance) Indicators) (الحر ارة، التبريد، الترطيب و التهوية). وسوف يتم دراسة امكانية التوصل الى كفاءة أفضل لأداء المبنى من طريق مقترح يتضمن

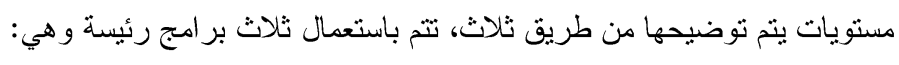
أ- Rhinoceros :Rhino Software- أو (Rhino3D) هو برنامج رسومات كمبيوثر ثلاثية الأبعاد او برنامج تصميم بمساعدة

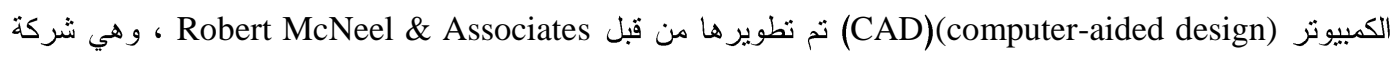
أمريكية

تابعة للقطاع الخاص تأسست عام .91 19 . تستند هندة مhinoceros على نموذج NURBS الرياضي، الذي يركز بدوره

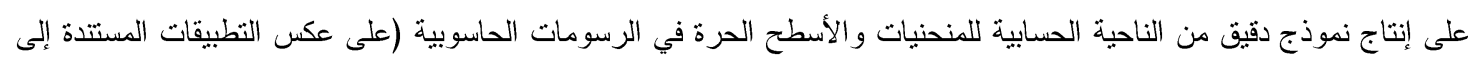
الثبكة المضلعة). Lhttps://www.rhino3d.com/resources

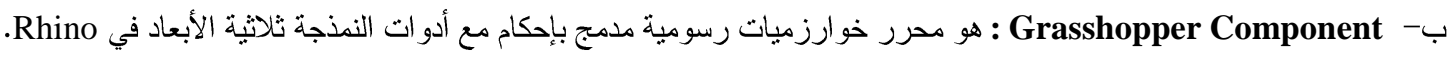

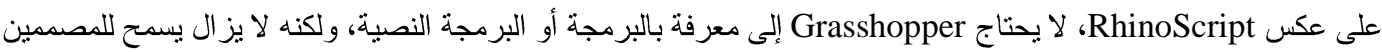

بيناء مولدات شكلية من البسيط إلى المعقد. [27]

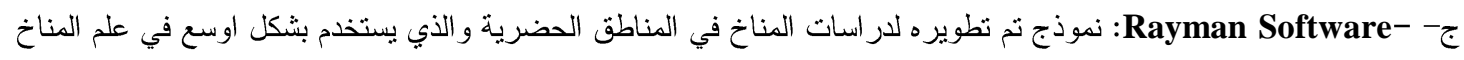

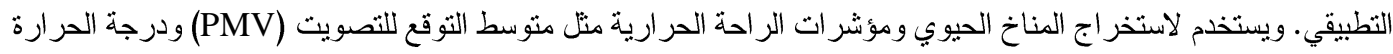


المكافئة الفيزيولوجية (PET) ودرجة الحرارة الفعالة (SET). كما ويشنثل ايضا على مخرجات مهمة مثل مدة التشمبس و التظليل و التي بمكن ان تشاعد في تصميم وتخطيط مناطق اعادة التوطين وتصميم المنشآت الحضرية. [28]

\section{5}

يتضمن هذا المستوى انثاء نموذج افتر اضي لمبنى متعدد الطوابق في بغداد بشكل مكعبي دونما تدخل من عمليات المحاكاة في تشكيله، وتحديده ب ^ا طابق كدد اعلى، وذلك في برنامج Rhino، وقياس شدة الاشعاع الحر ارب الثمسي من طريق برنامج Grasshopper

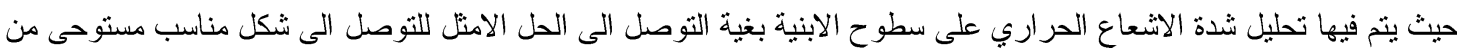
ادائية المبنى في تللك الييئة. يتم ذلك من طريق مكون (component) يدعى (Environmental Analysis) وتحديدا (A) Radiation) (Analysis في الجزء التحليلي من الإطار العملي. ونلاحظ من خلال الثكل اعتماد اليوم الاثد حرارة في السنة في شهر تموز وتحديدا منتصف تموز من الساعة الثالثة الى الر ابعة عصر اكونها الساعة الاكثر حرارة خلال اليوم. حيث يتم عمل الخوارزمية من طريق الخطوات التالبة:

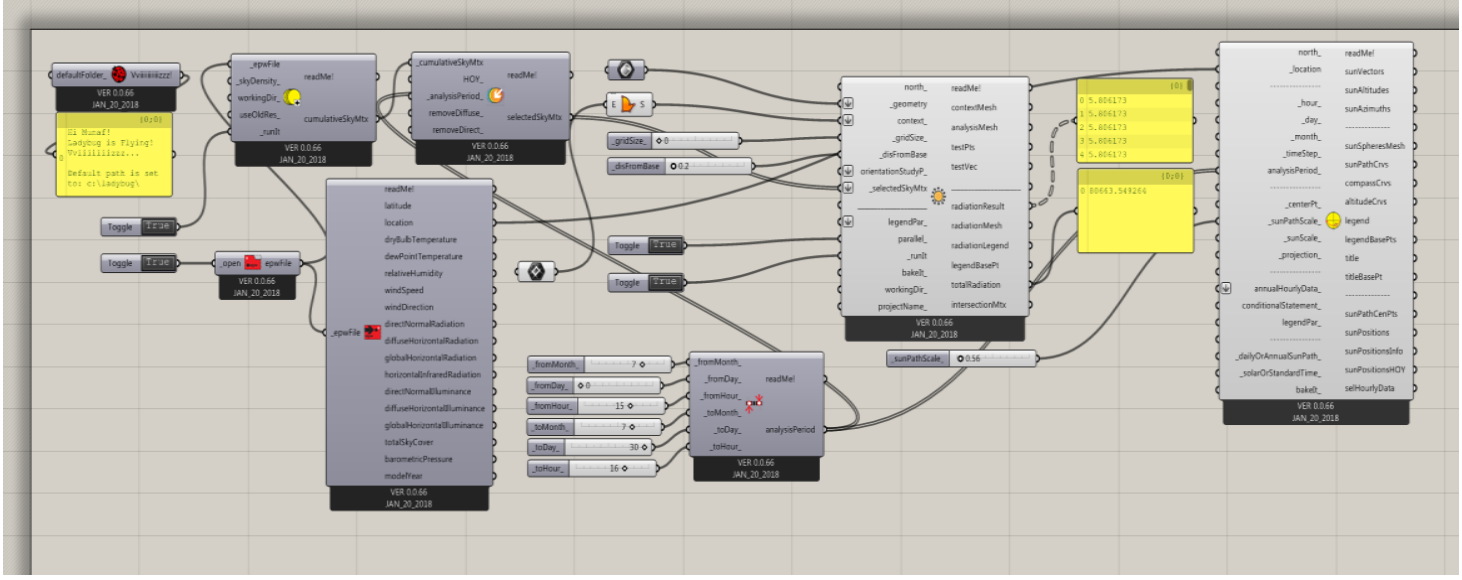

شكل(Y) يوضت الخوارزمية المتبعه لرسم وقياس نموذج افتر اضي تقليدي لمبنى متعدد الطوابق قبل تطبيق المحاكاة الادائية المصدر: الباحث ضمن برنامج Grasshopper

أ-عمل نمذجة لنثكل تقليدي صندوقي غير مناثر بالبيئة وذلك في برنامج Rhino، وذلك من طريق ادات رسم المكعب وبابعاد محددة وبارتفاعه ا طابق كما موضح في شكل(r).

ب-ربط الثكل المرسوم في الراينو في ايعاز الكراسهوبر لبداية تخطيط الخوارزمية المخصصة لايجاد الاشعاع الحراري الذي يتعرض له سطح المضيف، وذلك من طريق رسم مستطيل وسطح مغلق في الكر اسهوبر وربطه مع السطح المرسوم في الر اينو،

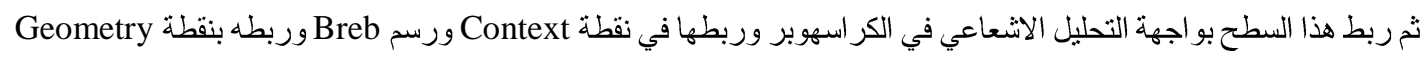

$$
\text { وتحديد موقع وحجم التحليل. }
$$

ج- نقوم بربط نقطة (SelectedSkyMtx) مع ايعاز (selectSkMtx) و التي بدور ها سترتبط في نقطنين،

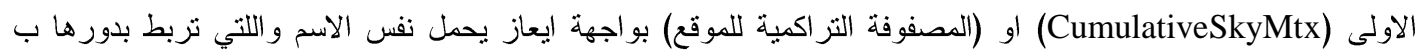
يتم من طريق ادخال ملف يحمل المعلومات المناخية للمنطقة ولتعذر وجود ملف منطقة الناصرية سوف يتم استعمال ملف مدينة الرياض و التي تحمل معلومات مقاربة لمناخ المنطقة والنقطة الثانية هي فترة التحليل (Analysis period) و التي وني يحدد عن طريقها الفترة الزمنية من حيث الساعات والايام والاشهر المر اد حسابها ضمن فتزة التحليل حيث سيتم اعتماد الفترة الاشد حرارة خلال السنة كمرجع تصميمي يتم اعتماده في عملية المحاكاة وترنبط هذه النقطة بنقطة اخرى وهي ايعاز مقياس 
المسار الثنمسي بالنسبة للمبنى وكما هو موضح في الثنكل حيث يتم التحكم بالمؤشر للوصول لحجم مناسب و التي ترتبط في نقطة Location بو المهة ايعاز Import epwFile و المرتبطة بدور ها بنفس الملف المناخي لمنطقة الدر اسة. وبالثالي سنتشكل لنا الخو ارزمية الوضحة في الثكل(ب). دـ عند اكتمال عملية ربط جميع الايعاز ات وتفعيل الايعاز ات المطلوبة ننتقل الى واجهة

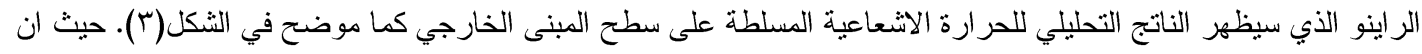
كل لون يظهر على السطح يؤشر مقدار معين من شدة وكمية الاشعاع الثمسي يظهر في دليل معين بالقرب من نموذج المبنى

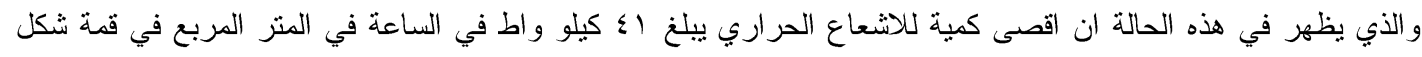

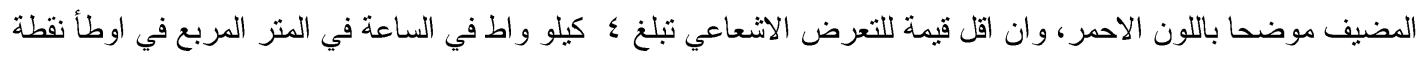
من شكل المضيف موضحا باللون الازرق الغامق.ه- يمكن حساب الاشعاع الكلي الذي يتعرض له سطح المبنى من طريق ايعاز Total radiation الحر اري في كل نقطه على سطح المبنى من طريق ايعاز Radiation result الكامن في المكان نفسه.

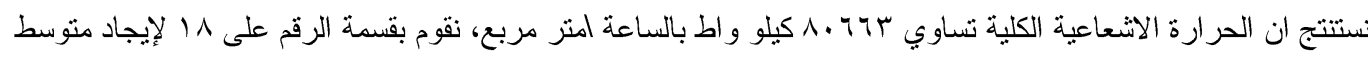

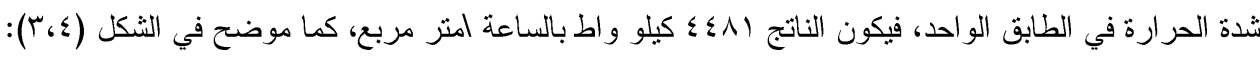

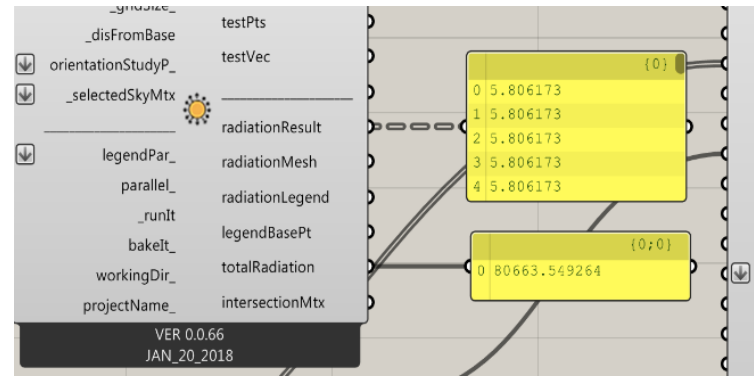

شكل (ع) يوضح الحرارة الاشعاعية الكلية في

Grasshopper المصدر: التطبيق العملي للباحث برنامج

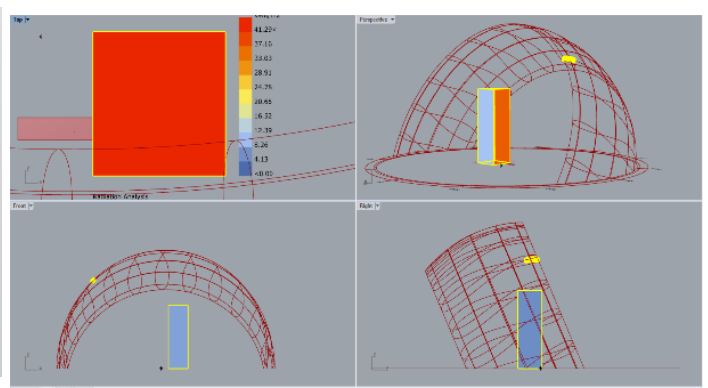

شكل (r) يوضح النموذج الافتر اضي للقياس

المصدر: التطبيث العملي للباحث في Rhino برنامج r, P

يتضمن هذا المستوى ارجاع القيمة المستخرجة من المستوى السابق (ثدة الاشعاع الحرار الكلية الساقطة على المبنى) الى برنامج RayMan ، من طريق الخطوات التالية: أ- تحويل وحدتها من كيلو واط في الساعةامتر مربع الى الدرجة السليزية،

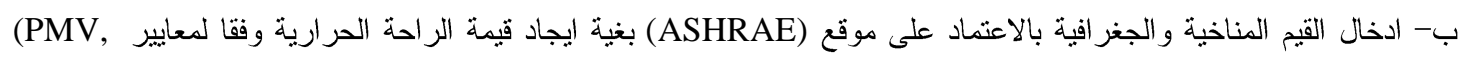
SET, PET)

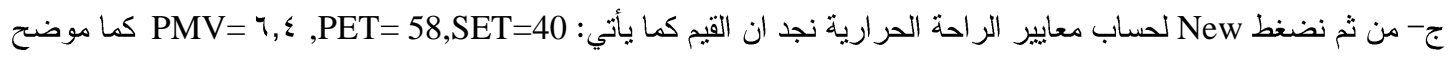
في شكل(ך) : 


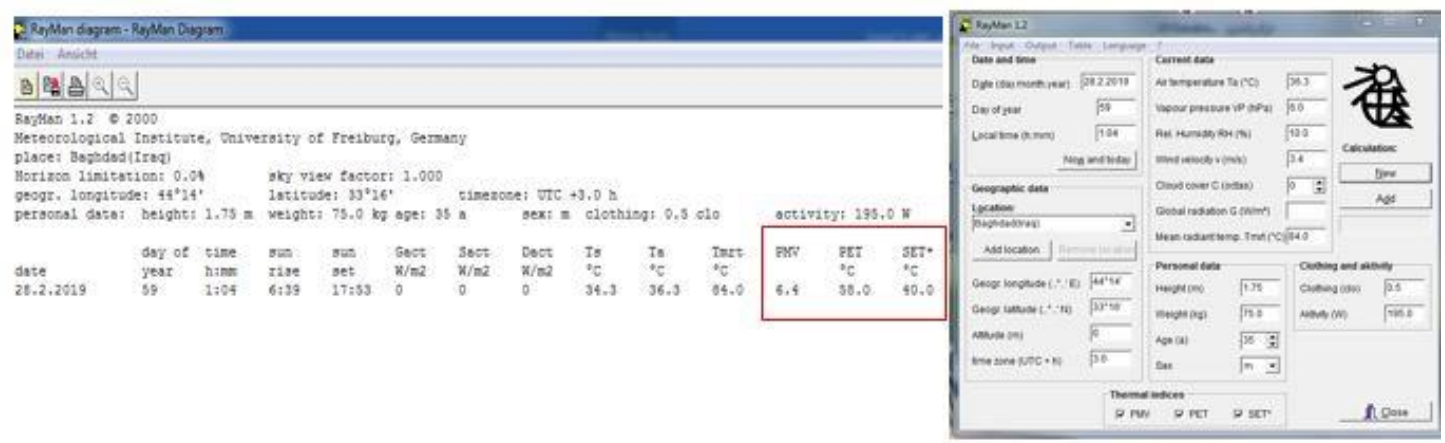

شكل (•) يوضح ادخال المدخلات في ش شكل (؟) يوضح النتائج المستخرجة من RayManومن ضنها المصدر: التطبيق RayMan برنامج معايير الراحة (PMV, SET, PET) برنامج المصدر: تطبيق الباحث الحرارية العملى للباحث

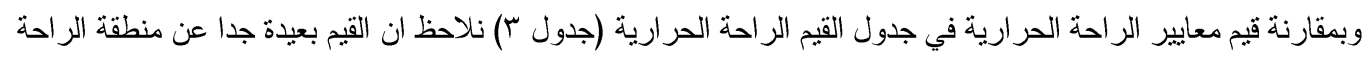

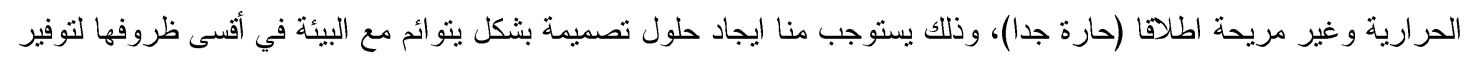

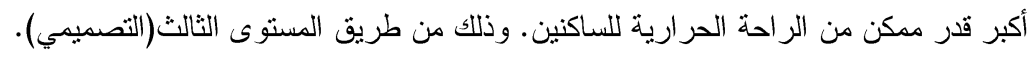

ه, ب المستوى التصميمي

حيث سيعتمد هذا المستوى على النتائج المستخلصة من المستويين السابقين، ابي الاهتمام بمعالجة المناطق الاكثر تعرضا لثنده

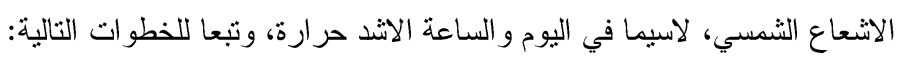

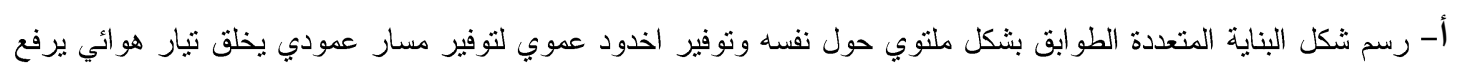

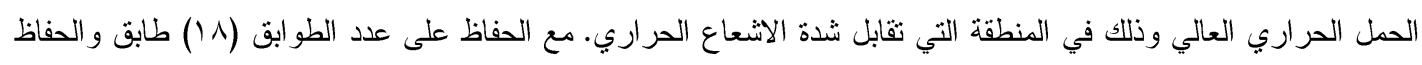

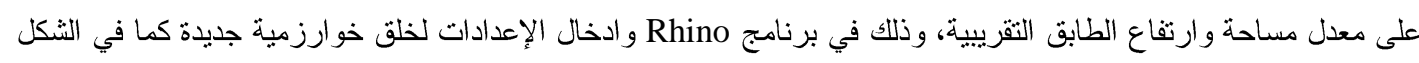

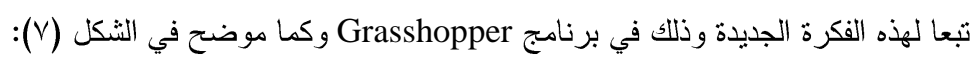

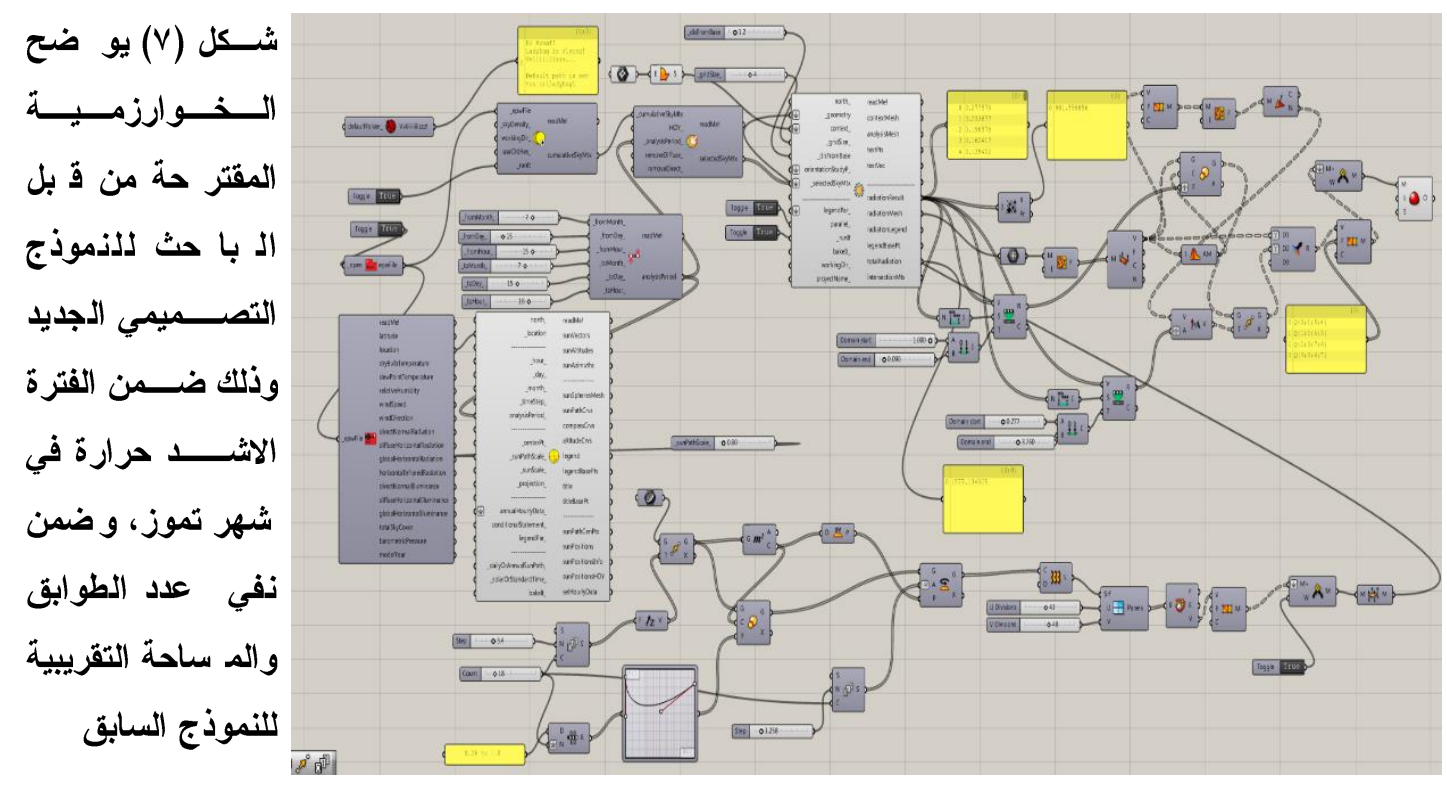


ب- خلق قشرة متكيفة مع البيئة Adaptive Skin من طريق الخوارزمية اعلاه والتي تتضمن المحافظة على الاعدادات الاساسية التي نم ذكرها في المستوى التحليلي، اضافة الى اعدادات جديدة تتضمن ربط نقطة RadiationMesh في قائمة تحليل الاشعاع

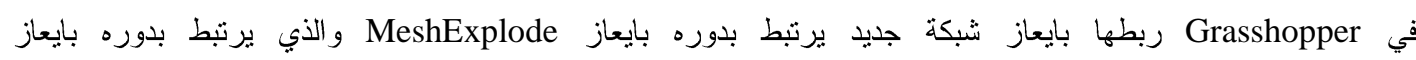
DeconstructMesh

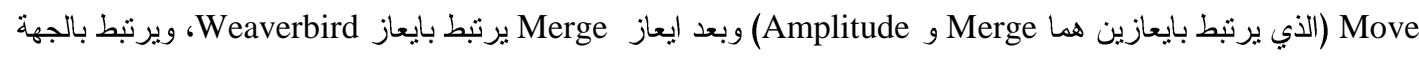
الثانية بايعاز Remap Number و التي تزنبط بدور ها بايعازي Bounds و Construct domain، و على الجانب الاخرربط

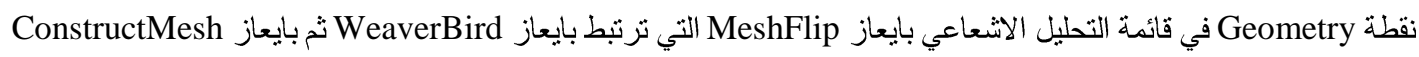
ومن ثم بايعاز Deconstruct Breb ثم بايعاز Pannel الذي ترتبط بايعاز ات Loft, Rotate, Scale وذلك لخلق القشرة التكيفية ذات فتحات شبكية مرتبطه بشكل اساسي بكمية الاشعاع الحر اري من طريق مقياس يعمل بطريقة عكسية ينغلق ويزداد عمقا كلما

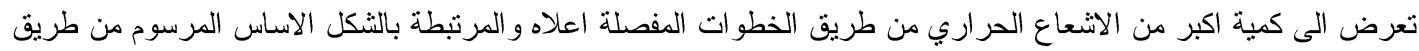

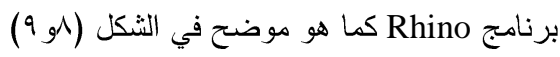

ج-حساب كمبة الاثعاع الحر اري الكلية التي ينعرض لها المبنى في برنامج Grasshopper نلاحظ انها تساوي 10VV كيلو و اط بالساعه امثر مربع ومن ثم تقسيم تلك الحر ارة على 1 ( لحساب منت سط شدة الاشعاع في الطابق الو احد، د- ادخال شدة الاشعاع الكلية في برنامج RayMan وذلك بعد تحويل الوحدات كما موضح في الثكل ( • () نلاحظ وصول قيمة الى ع, r وقيمة SET PMV
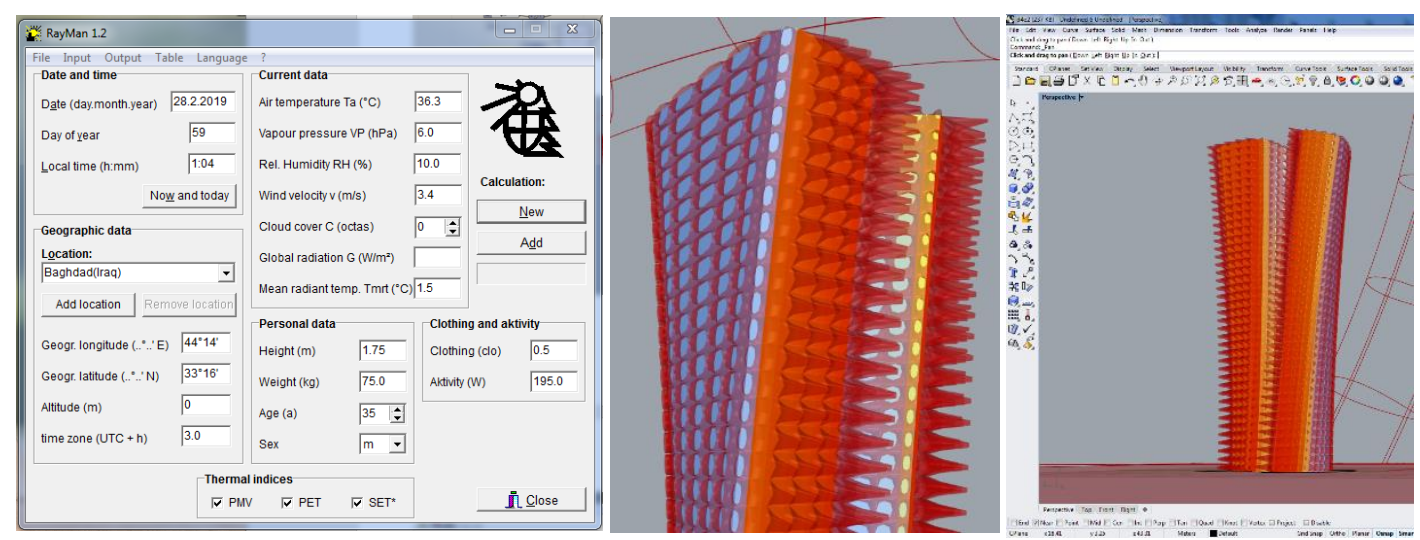

$$
\text { شكل ( • (1) يوضح قيم المدخلات من }
$$

RayMan

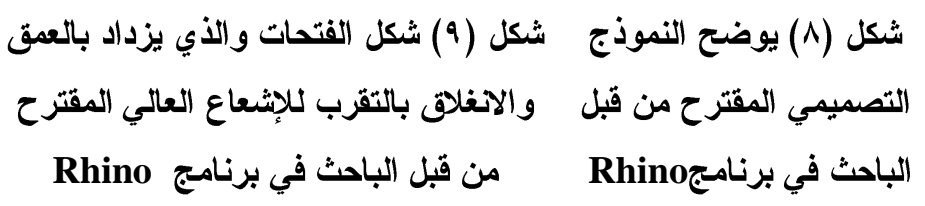

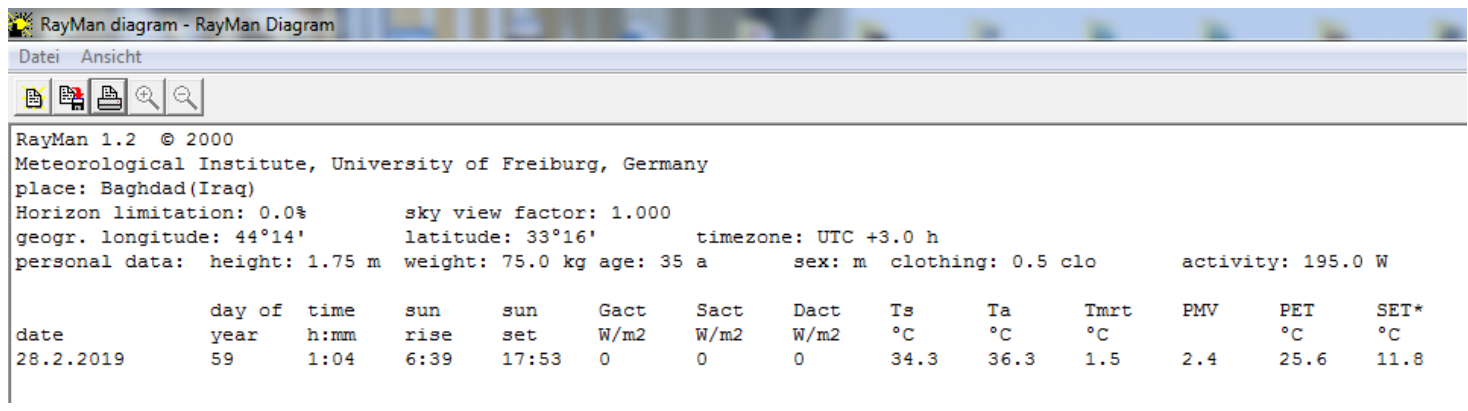


نلاحظ بمقارنة قيم المعايير (الحرارية لنتائج المحاكاة بالقيم الاصلية للشكل الاصلي في جذول(؟)، نلاحظ نجاح وكفاعة

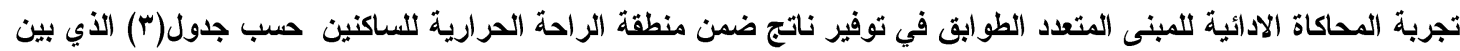
سابقا قيم الراحة الحرارية وفقا لمعايير (PMV, SET, PET) وذلك ضمن خطة عمل تناولت ب جواتب اساسية :الثكل الاساسي جئ الملتوي وفقا للحركة الثمسية، خلق محور عمودي للتهوية يحمل العبء الحراري المتكون، والجاتب الثالث هو خلق قثرة تكيفية تحيط بالمبنى وتستجيب لثدة الاشعاع الحراري تنغلق ويزداد عمقها كلما ازداد الاشعاع الحراري.

\begin{tabular}{|c|c|c|c|c|}
\hline \multicolumn{5}{|c|}{ 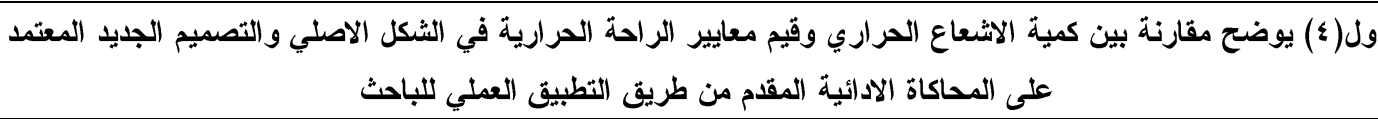 } \\
\hline PET & SET & PMV & شWh/m² شدة الاشعاع الحراري & النموذج \\
\hline 58 & 40 & 6.4 & 80663 & النموذج التقليدي \\
\hline 25.6 & 11.8 & 2.4 & 1577 & نموذج المحاكاة \\
\hline
\end{tabular}

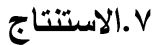

ان طريقة العمل بالمستويات الثثلاث (التحليلي،القياسي،التصميمي) و التي نت اتباعها للتوصل الى حلول توفر اشكال تصميمة

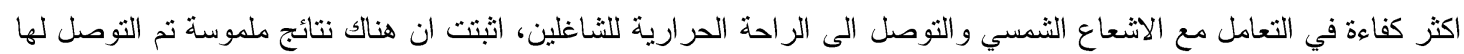

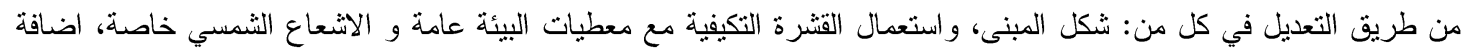
الى استثمار الثنكل الملتوي والفجوة العمودية لخلق تيار هوائي، وان تلك النتائج بالتالي تؤشر امكانيات انثاء مباني متعددة الطوابق، تصل الى ^ا طابق في بغداد، وذلك من طريق دراسة وتحليل الجوانب البيئية و الاستتاد الى حلول المعالجات التي تقدمها المحاكاة

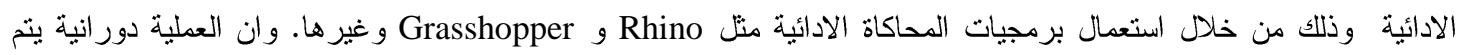

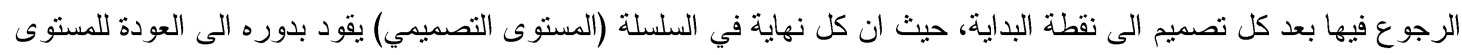

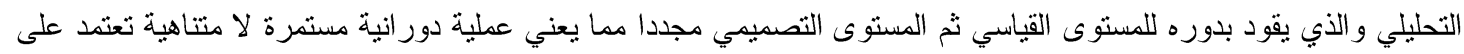

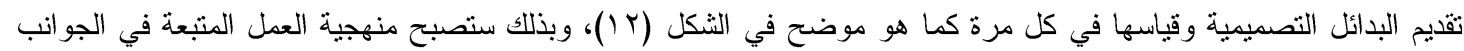

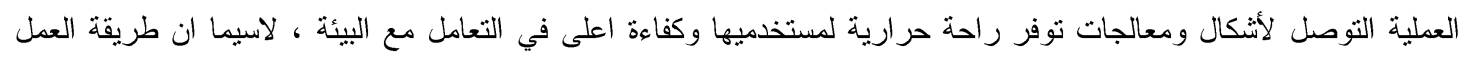

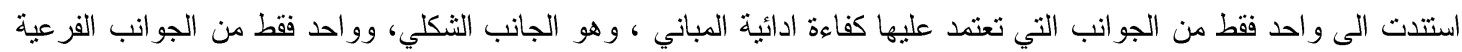

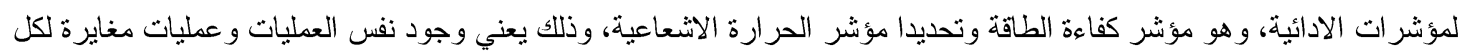
واحد من تنلك المؤشرات.

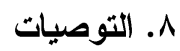

مما تقدم، تم در اسة وتحليل أحد مؤشر ات الادائية وهو مؤشر الر احة الحر ارية للساكنين، ضمن در اسة الثكل الخارجي للمبنى

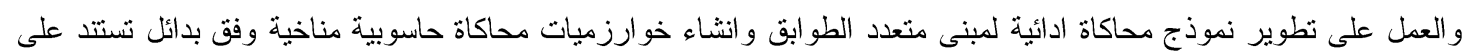
توظيف الثكل في خلق بيئة أقرب الى المثالية للساكن، فضلا عن توظيف قشرة المبنى في حماية المناخ الداخلي من الارتفاع الكبير لارجات الحر ارة، لاسيما في المباني المرتفعة متعددة الطو ابق وتعديل التصميم ليستثر التيار ات الهو ائية لتخفيف الاحمال الحرارية.

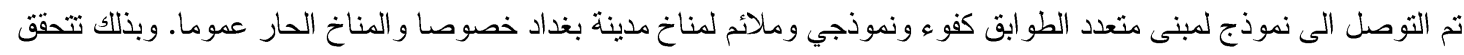
فرضية البحث بإمكانية تطوير نموذج حاسوبي بحاكي واقع الحال المحلي تم عن طريقه التوصل الى توفير بيئة مناخية ذات كفاءة

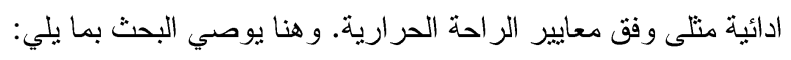
سدر اسة وتحليل كل مؤشر من مؤشر ات الادائية لما فيها من مستويات منكاملة نؤدي الى نتائج مثالية. -انثاء محاكاة جديدة وفقا للعو امل الاخرى المؤثزة على ادائية المبنى وكفاءته، منت الاعتبار ات الحضرية وتموضع المبنى في البيئة و النسيج فضلا عن در اسة تأثثير النباتات في الموقع. 


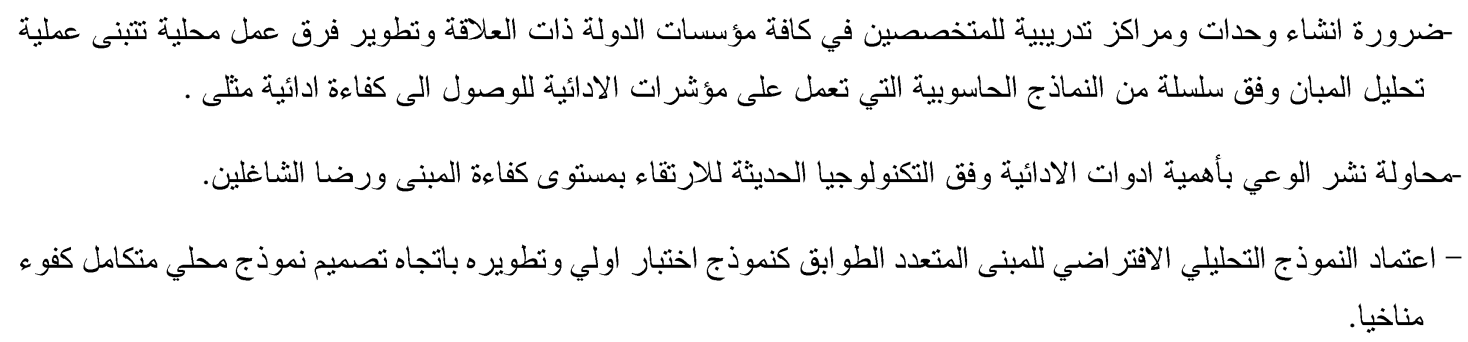

\section{CONFLICT OF INTERESTS.}

- There are no conflicts of interest.

\section{References}

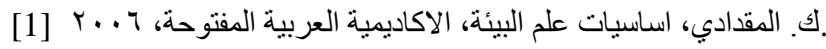

[2] H. Mifflin, Dictionary Of English Language, Hougton, 200.

[3] Yeang, The Green Skysraper, 199.

[4] S. C. ,. Van Der Ryn, " Ecological Design", U.S.A,: Island Press, 1996.

[5] M. Webster, Webster's Dictionary, 1989.

[6] K. T. Fatah, Ecological Design, 2012.

[7] M. Summers, "Eco-Friendly It Solutions That Minimise Environmental Damage And Save Natural Resource, Magora, 2017.

[8] D. L. Johnson, S. H. Ambrose, T. J. Bassett, M. L. Bowen, D. E. Crummey, J. S. Isaacson, D. N. Johnson, P. Lamb, M. Saul And A. E. Winter-Nelson, "Meanings Of Environmental Terms," Journal Of Environmental Quality, P. 26, 1997.

[9] D. Symons, The Evolution Of Human Sexuality, New York: Oxford University Press, 1979.

[10] B. Berge, The Ecology Of Building Material, Oxford: Elsevier, 2009.

[11] A. M. Michael Hensel, Versatility And Vicissitude, Performance In Morpho-Ecological Design, Wiley, 2008.

مجلة الإمارات للبحوث الهنسية ",. ا. ،. س. بابان، "دور مناهج محاكاة الطبيعة على ستراتيجيات البناء الثكلي المستدام [12] 2008.

[13] P. D. Sushant Verma, Adaptive[Skins]: Responsive Building Skin Systems Based On Tensegrity Principles.

[14] B. F. R. C. Fan Shu-Yang, Principles And Practice Of Ecological Design, 2004.

[15] B. Kolarevic And A. M. Malkawi, Performative Architecture Beyond Iistrumentality, London: Spon Press, 2005.

[16] S. Hagan, Digitalia, 2008.

[17] Banks, Carson, Nelson And Nicol, Discrete-Event System Simulation, Prentice Hall, 2001.

[18] P. De Wilde, Building Performance Analysis, Chichester: Wiley-Blackwell, 2018.

[19] Clarke, Energy Simulation In Building Design, 2001. 
Journal of University of Babylon for Engineering Sciences, Vol. (27), No. (2): 2019.

[20] C. T. Fitz-Gobbon, Performance Indicators, 1990.

[21] G. Augenbroe, A Framework For Rational Building Performance Dialogues, 2005.

[22] J. V. Hoof, J. Hensen And M. Mazej, "Thermal Comfort: Research And Practice," Research Gate, 2010 .

[23] D. De Dear, Richard, Brager And Gail, Developing An Adaptive Model Of Thermal Comfort And Preference, 1998.

[24] Fanger And P.O., "Thermal Comfort: Analysis And Applications In Environmental Engineering," 1970.

[25] Gagge, Fobelets And Berglund, A Standard Predictive Index Of Human Response To The Thermal Environment, 1986.

[26] T. Honjo, Thermal Comfort In Outdoor Environment, Chiba: Faculty Of Horticulture, Chiba University, 2018.

[27] Tedeschi And Arturo, Intervista A David Rutten", Naples: Mixexperience, 2011.

[28] A. Matzarakis, Application Of The Rayman Model In Urban Environments, 2010.

\section{Websites}

/https://www.rhino3d.com/resources 